\title{
Exploiting Single Photon Vacuum Ultraviolet Photoionization to Unravel the Synthesis of Complex Organic Molecules in Interstellar Ices
}

\author{
Matthew J. Abplanalp ${ }^{1,2}$, Marko Förstel ${ }^{1,2}$, Ralf I. Kaiser ${ }^{1,2, *}$, \\ ${ }^{1}$ W. M. Keck Research Laboratory in Astrochemistry, University of Hawaii at Manoa, Honolulu, \\ Hawaii, HI, 96822, USA \\ ${ }^{2}$ Department of Chemistry, University of Hawaii at Manoa, Honolulu, Hawaii, HI, 96822, USA
}




\begin{abstract}
Complex organic molecules (COM) such as aldehydes, ketones, carboxylic acids, esters, and amides are ubiquitous in the interstellar mediums, but traditional gas phase astrochemical models cannot explain their formation routes. By systematically exploiting on line and in situ vacuum ultraviolet photoionization coupled with reflectron time of flight mass spectrometry (PI-ReTOFMS) and combining these data with infrared spectroscopy (FTIR), we reveal that complex organic molecules can be synthesized within interstellar ices that are condensed on interstellar grains via non-equilibrium reactions involving suprathermal hydrogen atoms at temperatures as low as $5 \mathrm{~K}$. By probing for the first time specific structural isomers without their degradation (fragment-free), the incorporation of tunable vacuum ultraviolet photoionization allows for a much greater understanding of reaction mechanisms that exist in interstellar ices compared to traditional methods thus eliminating the significant gap between observational and laboratory data that existed for the last decades. With the commission of the Atacama Large Millimeter/Submillimeter Array (ALMA), the detection of more complex organic molecules in space will continue to grow - including biorelevant molecules connected to the Origins of Life theme and an understanding of these data will rely on future advances in hard core physical chemistry laboratory experiments.
\end{abstract}




\section{INTRODUCTION}

Complex organic molecules (COMs) - per astronomical definition organic molecules containing several atoms of carbon, hydrogen, oxygen, and nitrogen such as (1) aldehydes (HCOR), (2) ketones (RCOR'), (3) carboxylic acids (RCOOH), (4) esters (RCOOR'), and (5) amides $\left(\mathrm{RCONH}_{2}\right)$ with $\mathrm{R}$ and $\mathrm{R}^{\prime}$ being an alkyl group - are ubiquitous in the gas phase of the interstellar medium (ISM) (Fig. 1) [1-4]. An understanding of the abiotic formation pathways of these key classes of complex organic molecules in distinct extraterrestrial environments (cold molecular clouds; star forming regions) is of core significance to the astrochemistry, astrobiology, and physical chemistry communities on multiple levels $[2,5,6]$.

First, the synthesis of complex organic molecules has been linked to the energetic processing of low temperature $(10 \mathrm{~K})$ ice-coated nanoparticles (interstellar grains) by ionizing radiation such as galactic cosmic rays (GCRs) and the ultraviolet (UV) photon field [7] in cold molecular clouds - the nurseries of stars and planetary systems - and in star forming regions [8-11]. Laboratory studies provided compelling evidence that the interaction of ionizing radiation with interstellar analog ices leads to a broad spectrum of complex organic molecules[12-34] including carboxylic acids like acetic acid $\left(\mathrm{CH}_{3} \mathrm{COOH}\right)$ [28,35-40], amines such as methylamine $\left(\mathrm{CH}_{3} \mathrm{NH}_{2}\right)$ [41], aldehydes like acetaldehyde $\left(\mathrm{CH}_{3} \mathrm{CHO}\right)[29,35,42,43]$, the sugar glycolaldehyde $\left(\mathrm{HCOCH}{ }_{2} \mathrm{OH}\right)[28,39,40,42,44]$, amino acids such as glycine $\left(\mathrm{H}_{2} \mathrm{NCH}_{2} \mathrm{COOH}\right)$ [45-51], and even dipeptides like glycine-glycine $\left(\mathrm{H}_{2} \mathrm{NCH}_{2} \mathrm{CO}-\mathrm{HNCH}_{2} \mathrm{COOH}\right)$ [52,53]. Interstellar ices consist of mixtures of water $\left(\mathrm{H}_{2} \mathrm{O} ; 100 \%\right)$, methanol $\left(\mathrm{CH}_{3} \mathrm{OH} ; 3-31 \%\right)$, carbon monoxide (CO; 3-26\%), carbon dioxide $\left(\mathrm{CO}_{2} ; 11-27 \%\right)$, methane $\left(\mathrm{CH}_{4} ; 1-3 \%\right)$, formaldehyde $\left(\mathrm{H}_{2} \mathrm{CO} ; 2-7 \%\right)$, ammonia $\left(\mathrm{NH}_{3} ; 7 \%\right)$, cyanate $\left(\mathrm{OCN}^{-} ; 0.1-1.9 \%\right)$, and carbonyl sulfide (OCS; 0.03-0.16\%), with percentages given with respect to water, [54] condensed on interstellar grains - carbonaceous and silicate-based nanoparticles with size distributions averaging to a few hundreds of nanometers (Table 1). The densest parts of cold molecular clouds ultimately undergo gravitational collapse eventually leading to star forming regions, which therefore resemble memory records of cold molecular clouds [55-57]. In these environments, heating from the central star can raise the temperatures up to $300 \mathrm{~K}$ thus leading to a (partial) sublimation of the complex organic molecules formed in the molecular cloud stage from the interstellar grains into the gas phase. Once in the gas phase, these species can be searched for and detected by radio telescopes via their rotational emissions in the microwave regime of the electromagnetic spectrum [58-66]. 

complex organic molecules are formed in those environments. A detailed understanding of the formation pathways of these key classes of complex organic molecules is therefore crucial to test chemical models of molecular clouds and of star forming regions as their synthetic pathways are constrained by physical (temperature, radiation) and chemical (composition) conditions of the interstellar environment [68-71].

Second, a detailed understanding of the synthesis of structural isomers - molecules with the same molecular formula but different connectivities of atoms - of complex organic molecules is of extreme importance as these molecules are utilized as tracers to determine the physical and chemical conditions of interstellar environments and to test chemical models of molecular clouds and star forming regions. Even the formation of the isomers of the isomeric triplets of $\mathrm{C}_{2} \mathrm{H}_{4} \mathrm{O}$, $\mathrm{C}_{3} \mathrm{H}_{4} \mathrm{O}$, and $\mathrm{C}_{2} \mathrm{H}_{4} \mathrm{O}_{2}$ comprising of acetaldehyde $\left(\mathrm{HCOCH}_{3}\right)$, vinyl alcohol $\left(\mathrm{C}_{2} \mathrm{H}_{3} \mathrm{OH}\right)$, and ethylene oxide $\left(\mathrm{c}-\mathrm{C}_{2} \mathrm{H}_{4} \mathrm{O}\right)$, propenal $\left(\mathrm{C}_{2} \mathrm{H}_{3} \mathrm{HCO}\right)$, cyclopropanone $\left(\mathrm{c}-\mathrm{C}_{3} \mathrm{H}_{4} \mathrm{O}\right)$, and methylketene $\left(\mathrm{CH}_{3} \mathrm{CHCO}\right)$, as well as acetic acid $\left(\mathrm{CH}_{3} \mathrm{COOH}\right)$, methyl formate $\left(\mathrm{HCOCH}_{3}\right)$, and glycolaldehyde $\left(\mathrm{HCOCH}_{2} \mathrm{OH}\right)$ has not been resolved conclusively to date (Fig. 2) [4,6,72-76]. Considering the $\mathrm{C}_{2} \mathrm{H}_{4} \mathrm{O}_{2}$ system, all three isomers have been detected toward the hot core Sagittarius B2 (Sgr. B2), but only methyl formate $\left(\mathrm{HCOCH}_{3}\right)$ has been observed in cold molecular clouds like the Orion Molecular Cloud-1 (OMC-1)[77]. Considering their key role as tracers for the evolution of molecular clouds and star forming regions, an understanding of their formation routes is, however, very important. Models of gas-phase-only-chemistry yield a factor of fractional abundances of complex organic molecules in the gas phase such as the $\mathrm{C}_{2} \mathrm{H}_{4} \mathrm{O}_{2}$ isomers of 50 to 100 less than observed. Mehringer et al. [78] suggested an alternative to gas phase reactions proposing that complex organic molecules are first formed on interstellar grains in cold molecular clouds at $10 \mathrm{~K}$ and then injected into the gas phase in star forming regions once the temperature of the grains increases and hence the newly formed molecules sublime [79-81]. Miller and Herbst [82,83] extended previous models and injected complex organic molecules, which formed inside interstellar ice-coated grains at $10 \mathrm{~K}$ through non-equilibrium chemistry and/or on their surfaces at temperatures exceeding $40 \mathrm{~K}$, via unexplored radical diffusion and recombination, to simulate these grain sublimation processes. However, even these refined models did not fit observed abundances of structural isomers of complex organic molecules such 

that key production routes to complex organic molecules involving interstellar grains are missing. Without any scientific justification, current astrochemical models simulating the formation of complex organic molecules on interstellar grains postulate that the ice mantle is chemically inert and that only the very first few monolayers of the ice surface take part in the synthesis of newly formed molecules. This limits the validity of currently existing models dramatically since it is well established that an interaction of ionizing radiation with ices of a few $100 \mathrm{~nm}$ thickness can lead to the formation of complex organic molecules via non-equilibrium processes inside the ices [10,24,84-89]. However, these processes have never been included comprehensively into astrochemical reaction networks modeling the formation of complex organic molecules in cold molecular clouds and star forming regions. Therefore, novel laboratory experiments probing the formation of complex organic molecules in interstellar analog ices via interaction of ionizing radiation are imperative. Next generation experimental techniques have to be exploited to obtain a more detailed and hence realistic understanding of the prebiotic organic chemistry inside interstellar ices.

Third, homologous series of complex organic molecules of carboxylic acids and amino acids for instance, have also been identified in meteorites such as the carbonaceous chondrite Murchison. Carbonaceous chondrites are considered as one of the most primitive remnants from the formation of the Solar System and provide an exceptional record of the organic chemical evolution in the early Solar System [90,91]. Therefore, a better understanding of the origin of complex organic molecules in carbonaceous chondrites is vital because they resemble natural time capsules before life developed on Earth. Hence, carbonaceous chondrites are important in their role as a repository of primitive organic material and are dubbed primordial fossils, helping to understand the chemical makeup of the early Solar System. Sophisticated ${ }^{13} \mathrm{C} /{ }^{12} \mathrm{C}$ and $\mathrm{D} / \mathrm{H}$ isotope analyses of Murchison's organic matter strongly propose an interstellar origin [92-94]. The densest parts of cold molecular clouds eventually undergo gravitational collapse to form primitive material, which in turn supplies the basic ingredients for planets, their moons, asteroids and cometary bodies; the isotopic analyses suggest that at least part of the organic material that initially formed in the molecular cloud and in star forming regions could have been incorporated into parent bodies of, for instance, the Murchison meteorite [95]. Consequently, the elucidation 
of synthetic routes leading to key classes of complex organic molecules in interstellar ices (Fig. 1) will help to constrain fundamental processes that drive the hitherto poorly characterized interstellar organic chemistry leading to the abiotic synthesis of complex organic molecules in interstellar ices. Hence, an experimental investigation on the formation of complex organic molecules brings us closer to understanding the extent to which key classes of these species might have been synthesized exogenously at a frozen stage $[95,96]$.

Finally, the investigation of the interaction of ionizing radiation with low temperature ices is of basic interest to the physical chemistry community considering that the initial bond-breaking processes occur under non-thermal (non-Arrhenius) and hence non-equilibrium conditions [97]. This does not only lead to the intial formation of carbon-, oxygen-, and nitrogen-centered radicals with significant vibrational excitation, but also to the release of suprathermal atoms, such as hydrogen, holding excess kinetic energies of a few electron volts [98-104]. Both, the excess vibrational and kinetic energy of the fragments, can be imparted in the transition state of a chemical reaction thus opening up classically (thermally) closed reactions under non-equilibrium conditions (Fig. 3). Exploiting an inverse Laplace transformation, these processes have been shown to hold suprathermal rate constants close to gas kinetics limits (few $10^{-10} \mathrm{~cm}^{3} \mathrm{~s}^{-1}$ ), which are orders of magnitude faster than the corresponding thermal reactions at $10 \mathrm{~K}\left(10^{-13} \mathrm{~cm}^{3} \mathrm{~s}^{-1}\right.$ $\left.10^{-70} \mathrm{~cm}^{3} \mathrm{~s}^{-1}\right)[98]$.

These considerations make it clear that despite the key role of complex organic molecules as a molecular 'clock' in understanding the astrochemical evolution of cold molecular clouds and star forming regions, the fundamental question of how these molecules are formed on interstellar grains has not been answered to date. The lack of crucial data (reaction products, branching ratios, rate constants of their formation and how they depend on the ice temperature and composition) has failed to deliver a coherent picture on the underlying formation mechanisms as demonstrated by the discrepancies of theoretically predicted and astronomically observed abundances of complex organic molecules and of structural isomers in particular. Based on these considerations, a high-level innovative experimental investigation of the formation of complex organic molecules is imperative to deliver much needed quantitative information on their formation, systematically and over a broad range of ice temperatures and composition. 


\section{HISTORICAL OVERVIEW}

A detailed understanding of the chemical processing of interstellar ice analog samples upon interaction with ionizing radiation and the inherent formation of key classes of complex organic molecules on a very fundamental level is crucial. These are surface experiments, in which monochromatic photons and/or monoenergetic charged particles are made to interact with interstellar ice analog samples under clean conditions. These laboratory experiments are conducted in simulation chambers typically held at ultra-high vacuum conditions of a few $10^{-11}$ torr which mimic the exposure of astrophysically relevant ices at low temperatures toward monoenergetic charged particles (protons, helium nuclei, electrons) and monochromatic photons [12-15,18,20, $21,27,31]$. The synthesis of newly formed molecules upon interaction of the cryogenically cooled ice surfaces is best traced spectroscopically on line and in situ in the condensed phase (ices) and simultaneously in the gas phase both during the irradiation of the ices and also in the warm up phase (temperature programmed desorption; TPD) leading to the sublimation of the newly formed molecules. The concerted analysis of the solid phase and the gas phase allows a correlation of, for example, the decay of an absorption feature in the ices with an increase of signal in the gas phase upon sublimation of a species of interest.

Historically, Fourier Transform Infrared spectrometry (FTIR) has been extensively used to monitor the response of astrophysical ice analogs in the laboratory toward ionizing radiation. Whereas FTIR spectroscopy presents an ideal tool to investigate the processing and decay kinetics of 'small' molecules such as carbon monoxide $(\mathrm{CO})$, water $\left(\mathrm{H}_{2} \mathrm{O}\right)$, methanol $\left(\mathrm{CH}_{3} \mathrm{OH}\right)$, carbon dioxide $\left(\mathrm{CO}_{2}\right)$, methane $\left(\mathrm{CH}_{4}\right)$, formaldehyde $\left(\mathrm{H}_{2} \mathrm{O}\right)$, along with ammonia $\left(\mathrm{NH}_{3}\right)$ - those molecules detected on interstellar grains (Table 1) - the ability of infrared spectroscopy to provide useful information for the detection of COMs formed within the ices is quite limited. Infrared spectroscopy allows the functional groups of COMs to be identified; however, this information does not always identify individual molecules since the functional groups of, for instance, carbonyls like aldehydes and ketones depict similar group frequencies in the range of $1850 \mathrm{~cm}^{-1}$ to $1600 \mathrm{~cm}^{-1}$ [105]. Therefore, the exclusive assignment of a single molecule based on infrared bands in an unknown mixture of COMs is rarely feasible - unless you know what you 'want to detect'. Even simple ices of carbon monoxide $(\mathrm{CO})$ and methane $\left(\mathrm{CH}_{4}\right)$ exhibit broad absorption features in the carbonyl stretching region after exposure to energetic electrons thus 
making it difficult to identify individual molecules (Fig. 4a) [29]. Hence, FTIR nicely aids in identifying new functional groups of complex organic molecules formed within the astrophysical ice analogs, but only in rare circumstances in the identification of individual molecules and of structural isomers in particular [106,107] (Fig. 2).

Besides FTIR in the condensed phase, mass spectroscopy exploiting a quadrupole mass spectrometer (QMS) coupled with electron impact ionization of the subliming molecules during the temperature programmed desorption (TPD) of the irradiated ices has been extensively used to identify newly formed molecules in the processed ices after their sublimation into the gas phase [108-114]. However, a typical QMS interfaced to a space simulation chamber using an electron impact ionizer operating at 70 to $100 \mathrm{eV}$ electron energy does not only ionize molecules, but also results in a significant fragmentation of the parent ion thus forming extensive fragment ions. In the worst case, this can lead to the absence of the molecular parent ion. Likewise, the fragment ions of structural isomers often overlap making it difficult to decipher and to even discriminate between structural isomers. Considering simple ices of carbon monoxide (CO) and methane $\left(\mathrm{CH}_{4}\right)$, the detection of complex organic molecules such as acetaldehyde $\left(\mathrm{CH}_{3} \mathrm{CHO} ; \mathrm{m} / \mathrm{z}=44\right)$ is complicated in the mass spectrometer by ion counts from carbon dioxide $\left(\mathrm{CO}_{2} ; \mathrm{m} / \mathrm{z}=44\right)$ and propane $\left(\mathrm{C}_{3} \mathrm{H}_{8} ; \mathrm{m} / \mathrm{z}=44\right)$, which represent dominating products in carbon monoxide and methane ices processed by ionizing radiation (Fig. 5) [29]. Exploiting soft ionization with low energy electrons of a few electron volt kinetic energy has only a limited advantage since the voltage drop across the filament results in a resolution of typically only $1.0 \mathrm{eV}$. Therefore, carbon dioxide $\left(\mathrm{CO}_{2}\right)$ with an ionization energy (IE) of $13.78 \mathrm{eV}$ might be separated from propane $\left(\mathrm{C}_{3} \mathrm{H}_{8} ; \mathrm{IE}=10.94 \mathrm{eV}\right)$, but the latter cannot be discriminated against acetaldehyde $\left(\mathrm{CH}_{3} \mathrm{CHO} ; \mathrm{IE}=10.23 \mathrm{eV}\right)$ and ethylene oxide $\left(\mathrm{c}-\mathrm{C}_{2} \mathrm{H}_{4} \mathrm{O} ; \mathrm{IE}=10.56 \mathrm{eV}\right)$. Likewise, the isomer triplet acetaldehyde $\left(\mathrm{CH}_{3} \mathrm{CHO} ; \mathrm{IE}=10.23 \mathrm{eV}\right)$ - ethylene oxide $\left(\mathrm{c}-\mathrm{C}_{2} \mathrm{H}_{4} \mathrm{O} ; \mathrm{IE}=10.56 \mathrm{eV}\right)-$ vinyl alcohol $\left(\mathrm{H}_{2} \mathrm{CCHOH}\right.$; $\left.\mathrm{IE}=9.33 \mathrm{eV}\right)$ can be hardly differentiated exploiting soft electron impact ionization considering that the ionization energies of these isomers fall within $1.5 \mathrm{eV}$.

Finally, a non-volatile residue is typically formed whenever carbon is present in the irradiated ices and the ices are exposed to doses higher than typically a few electron volts per molecule [14,50,115-117]. The residue, which is often insoluble in classical solvents, consists of a complex mixture of chemical components and represents often an ill-defined polymer-type structure 

frequencies, but this method fails once more to identify individual molecules in the residues. Traditionally, these residues are exposed to harsh conditions such as acid-assisted hydrolyses before derivatizing the hydrolysis products as, for instance, volatile trimethylsilyl derivatives ($\left.\mathrm{Si}\left(\mathrm{CH}_{3}\right)_{3}\right)$ to be analyzed off line via gas chromatography - mass spectrometry (GC-MS) [48, $115,116,118]$. Naturally, this treatment may lead to chemical modification and degradation of the residues to the individual molecular building blocks of the polymeric residue. The recent identification of dipeptides along with the corresponding suite of fully isotopically substituted counterparts such as glycine-glycine and alanine-glycine in residues of electron irradiated ices containing carbon dioxide, ammonia, and hydrocarbons clearly highlights the obligation to analyze the residues under mild conditions to avoid hydrolysis and incorrect assignment of 'products' formed in the irradiation of ices (Fig. 6) [52].

\section{EXPERIMENTAL APPROACH}

\subsection{SINGLE PHOTON IONIZATION}

Considering the limitations of traditional analytical techniques (FTIR, QMS, GC-MS), it is clear that a radically different approach and new expertise exploring creative and transformative concepts in laboratory astrophysics is required to understand the formation of complex organic molecules upon interaction of ionizing radiation with astrophysically relevant ices. Here, a detailed understanding of the chemical processing of these samples on a very fundamental level is crucial. Surface experiments, in which monochromatic photons and/or monoenergetic charged particles are made to interact with interstellar ice analog samples under clean conditions as provided via ultra-high vacua (UHV) are able to provide this understanding. These experiments must also be carried out with astrophysically relevant temperatures, chemical compositions, and radiation sources; they should further interface complementary analytical detection schemes to follow the formation of functional groups of key molecular classes in the condensed phase (ices) and also individual newly formed molecules in the gas phase during sublimation of the ice samples via warm up on line and in situ. Here, we pioneer interfacing complementary detection schemes to a single machine [25-30,119,120]. This enables us to identify key functional groups of complex organic molecules such as $\mathrm{C}-\mathrm{O}, \mathrm{C}=\mathrm{O}$, and $\mathrm{COOH}$ on line and in situ in the solid state 

with soft photoionization by simultaneously monitoring the decay signal of relevant functional groups in the condense phase via FTIR. By softly ionizing the subliming molecules in the gas phase via single photon ionization and successive detection of the photoionized molecules via a reflectron time-of-flight mass spectrometer (PI-ReTOF-MS), we monitor the complete product spectrum based on distinct mass-to-charge ratios of the ionized molecules. Considering that the majority of the relevant molecules have ionization energies between $8 \mathrm{eV}$ and $14 \mathrm{eV}$, vacuum ultraviolet (VUV) light is required for the photoionization process. Further, since the energy of the photon can be 'controlled' within a resolution of at least $0.01 \mathrm{eV}$, the subliming molecules can be photoionized according to their known ionization energies. Since distinct complex organic molecules hold discrete ionization energies (Fig. 2), a correlation of the ionization energy with the mass-to-charge of the product helps to uniquely identify individual complex organic molecules and in particular their isomers. The ideally fragment-free isomer-specific detection of individual isomers represents the key advantage of single photon vacuum ultraviolet photoionization compared to traditional mass spectrometry with electron impact ionization. Since the subliming molecules and structural isomers can also be separated via fractionated sublimation according to their sublimation temperatures, the sublimation sequence along with the correlation of the ionization energy with the mass-to-charge of the product represents a versatile and powerful approach to uniquely identify the nature of the complex organic molecules formed.

\subsection{THE SIMULATION CHAMBER}

The centerpiece of the experimental setup is a stainless steel chamber of 100 liter volume, which is evacuated by clean, oil-free, magnetically levitated turbo molecular pumps coupled to oil-free scroll backing pumps to pressures of a few $10^{-11}$ torr (Fig. 7) $[25,29,30]$. These UHV conditions are crucial for the success of the experiments, since they avoid contamination and cocondensation of residual gases with and on the ices throughout the duration of an experiment limiting the condensation of one monolayer of residual gases onto the ices to about 30 hours. Second, we must generate low temperature ices in the machine. Ices of typically $500 \mathrm{~nm}$ thickness are prepared on a surface of $1 \mathrm{~cm}^{2}$ (rhodium coated) silver wafer in situ by condensing a gas mixture prepared separately in a gas mixing chamber via a capillary array onto a cryogenic 
finger; the latter is interfaced to a two-stage closed cycle helium refrigerator. The ionizing radiation interacts with the ices, but the charged particles do not reach the silver wafer. The temperature of the samples can be adjusted between $5 \mathrm{~K}$ and $300 \mathrm{~K}$ to simulate astrophysically relevant temperatures in cold molecular clouds and star forming regions. The chemical modification of the processed ices and hence functional groups of the newly formed molecules are monitored on line and in situ via infrared spectroscopy $\left(10,000 \mathrm{~cm}^{-1}\right.$ to $\left.500 \mathrm{~cm}^{-1}\right)$. The on line and in situ operation of the spectrometer is a crucial prerequisite to elucidate the formation of new molecules and functional groups over the experimental time. Typically, the infrared spectra are averaged for a few minutes during the irradiation, while actual irradiation times range up to a few hours. By following the evolution of the absorption bands of distinct molecules and of functional groups over time, we extract time-dependent concentration profiles and hence production rates of newly formed species. By solving the coupled differential equations, these timedependent profiles can be fit kinetically to derive the underlying reaction mechanisms yielding complex organic molecules like the sugar glycolaldehyde (Fig. 8) [28,39].

\subsection{VACUUM ULTRAVIOLET LIGHT GENERATION}

We incorporate fragment-free single photon soft photoionization utilizing tunable vacuum ultraviolet light (VUV) in our machine. This presents the very first time that photoionization coupled to a reflectron time-of-flight mass spectrometer (PI-ReTOF-MS) is integrated into a space simulation chamber to probe molecules formed upon interaction of ionizing radiation following sublimation. The products released into the gas phase are sampled via a reflectron time-of-flight mass spectrometer based on the mass-to-charge ratios of the neutral molecules after their ionization. Although electron impact presents a widely used approach to ionize gas phase molecules, this method cannot be easily applied to discriminate structures of organic molecules in the present experiments (2. Historical Overview). Further, electron impact ionization leads to fragmentation of the parent, which can severely decrease or even eliminate the signal of the parent molecule entirely. For example, electron impact ionization of glycolaldehyde $\left(\mathrm{HCOCH}_{2} \mathrm{OH}\right)$ or acetic acid $\left(\mathrm{CH}_{3} \mathrm{COOH}\right)$ fragments the parent ion at $\mathrm{m} / \mathrm{z}=60$ (Fig. 9) extensively to $\mathrm{m} / \mathrm{z}=29\left(\mathrm{HCO}^{+}\right)$and $31\left(\mathrm{CH}_{2} \mathrm{O}^{+}\right)$, or $\mathrm{m} / \mathrm{z}=43\left(\mathrm{CH}_{3} \mathrm{CO}^{+}\right)$and $45\left(\mathrm{COOH}^{+}\right)$, respectively, whereas photoionization at $10.60 \mathrm{eV}$ results in a very clean spectrum showing only the parent peak at $\mathrm{m} / \mathrm{z}=60$. Consequently, electron impact ionization cannot be used in the pre- 

they sublimate into the gas phase during temperature programmed desorption and in situ analysis.

To photoionize the molecules, vacuum ultraviolet (VUV) light from $5 \mathrm{eV}$ to $14 \mathrm{eV}$ at fluxes of $10^{13}-10^{15}$ photons pulse ${ }^{-1}$ is generated by utilizing resonance enhanced sum $\left(2 \omega_{1+} \omega_{2}\right)$ and difference $\left(2 \omega_{1}-\omega_{2}\right)$ frequency nonlinear mixing, normally referred to as 'resonant enhanced four wave mixing' by accessing the different resonance lines of krypton and xenon. [121,122]. Here, pulsed VUV light $\left(\omega_{\text {vuv }}\right)$ is generated with the aid of two dye lasers (Sirah, Precision Scan) pumped each by an individual Nd:YAG laser (Spectra Physics, PRO-250-30); this generates the UV $\left(\omega_{1}\right)$ output necessary to generate the resonant line $\left(2 \omega_{1}\right)$ in the gas medium and tunable photon frequencies in the visible (VIS) range $\left(\omega_{2}\right)$ (Fig. 10). The VUV light is thus generated, including the sum $\left(2 \omega_{1}+\omega_{2}\right)$, and difference-frequency $\left(2 \omega_{1}-\omega_{2}\right)$, along with the fundamental $\omega_{1}$ and $\omega_{2}$ beams and a minor fraction of frequency tripled ( $\left.3 \omega_{\mathrm{uv}}\right)$. The separation of the unwanted fundamental frequencies $\left(\omega_{1}\right.$ and $\left.\omega_{2}\right)$ may be accomplished using a bi-convex lens off axis, where the UV and visible beams diverge due to the different indices of refraction [123]. The biconvex lens however significantly reduces the tuning range of the VUV light as the material typically used $(\mathrm{LiF})$ becomes opaque at around $105 \mathrm{~nm}$. Conversely, no separation of the light is desired especially for molecules that have higher ionization potentials than $11.8 \mathrm{eV}(105 \mathrm{~nm})$. In the case of a photon energy greater than $11.8 \mathrm{eV}$, a differentially pumped capillary can be incorporated acting as a light guide to deliver the VUV photons to the photoionization region [124].

\section{PROTOTYPE SYSTEMS}

To demonstrate the potential of the PI-ReTOF-MS approach, we are highlighting selected experimental results of key systems containing carbon monoxide (CO). According to a recent Spitzer survey, carbon monoxide represents one of the most dominant components of interstellar ices with abundances of up to $20 \%$ relative to water ice [125]. Carbon monoxide represents further the backbone of the carbonyl functional group in aldehydes, ketones, and sugars and is also a building block of the peptide bond. An energetic processing of ices containing carbon monoxide will therefore access several key classes of complex organic molecules as compiled in Figure 1. 


\subsection{THE CO $-\mathrm{CH}_{4}$ SYSTEM 4.1.1. CONDENSED PHASE - FTIR}

During the irradiation, multiple new absorption features emerged (Fig. 4a). These could be assigned to six discrete (small) molecules with well-established fundamentals. These are the methyl radical $\left(\mathrm{CH}_{3}\right)\left(3151 \mathrm{~cm}^{-1}, v_{3} ; 613 \mathrm{~cm}^{-1}, v_{2}\right)[43,85,126]$, the formyl radical (HCO) (1853 $\left.\mathrm{cm}^{-1}, v_{3} ; 1091 \mathrm{~cm}^{-1}, v_{2}\right)$ [43], the $\mathrm{C} 2$ hydrocarbons acetylene $\left(\mathrm{C}_{2} \mathrm{H}_{2}\right)\left(3253 \mathrm{~cm}^{-1}, v_{2}\right)$ [85,127], ethylene $\left(\mathrm{C}_{2} \mathrm{H}_{4}\right)\left(3093 \mathrm{~cm}^{-1}, v_{9}\right)$ [128], and ethane $\left(\mathrm{C}_{2} \mathrm{H}_{6}\right)\left(2978 \mathrm{~cm}^{-1}, v_{10} ; 2962 \mathrm{~cm}^{-1}, v_{1} ; 2920\right.$ $\left.\mathrm{cm}^{-1}, v_{8}+v_{11} ; 2885 \mathrm{~cm}^{-1}, v_{5} ; 1466 \mathrm{~cm}^{-1}, v_{11} ; 1373 \mathrm{~cm}^{-1}, v_{6}\right)[85,128]$ and eventually carbon dioxide $\left(\mathrm{CO}_{2}\right)\left(2341 \mathrm{~cm}^{-1}, v_{6}\right)$ [113]. All assignments were confirmed via their isotopic shifts in $\mathrm{CD}_{4}-\mathrm{CO}, \mathrm{CD}_{4}-{ }^{13} \mathrm{CO}$, and $\mathrm{CH}_{4}-\mathrm{C}^{18} \mathrm{O}$ ices (Table $2 \mathrm{a}$ ).

Besides these small individual molecules, a broad absorption feature which can be correlated with the carbonyl stretching mode emerged with the onset of irradiation at around $1727 \mathrm{~cm}^{-1}$. Since this feature is significantly broadened toward the low and high frequency sides, multiple underlying carriers are anticipated. These underlying carriers can be identified by deconvoluting the $1727 \mathrm{~cm}^{-1}$ feature, and we found five bands at $1746 \mathrm{~cm}^{-1}, 1727 \mathrm{~cm}^{-1}, 1717 \mathrm{~cm}^{-}$ ${ }^{1}, 1701 \mathrm{~cm}^{-1}$, and $1660 \mathrm{~cm}^{-1}$, which can be correlated with multiple functional groups from literature data. These studies propose that the band at $1727 \mathrm{~cm}^{-1}$ might be assigned to the $v_{4}$ fundamental of acetaldehyde $\left(\mathrm{CH}_{3} \mathrm{CHO}\right)$ [43,129]. The deconvoluted band at $1746 \mathrm{~cm}^{-1}$ can be assigned to saturated aldehydes with alkyl functional groups such as propanal $\left(\mathrm{C}_{2} \mathrm{H}_{5} \mathrm{CHO}\right)$ and butanal $\left(\mathrm{C}_{3} \mathrm{H}_{7} \mathrm{CHO}\right)[130,131]$. The absorption at $1717 \mathrm{~cm}^{-1}$ can be attributed to alkylketones such as acetone $\left(\mathrm{CH}_{3} \mathrm{COCH}_{3}\right)$ and/or higher alkyl groups such as methylethylketone $\left(\mathrm{CH}_{3} \mathrm{COC}_{2} \mathrm{H}_{5}\right)$ and even diethylketone $\left(\mathrm{C}_{2} \mathrm{H}_{5} \mathrm{COC}_{2} \mathrm{H}_{5}\right)$ [132,133]. The infrared absorption at $1701 \mathrm{~cm}^{-1}$ can be assigned to $\alpha, \beta$-unsaturated aldehydes/ketones with the lower frequency attributable to the $\alpha, \beta$ unsaturation and therefore lowering of the frequency due to resonance of the structure [105]. Finally, the absorption band at $1660 \mathrm{~cm}^{-1}$ can be linked to $\alpha, \beta$-dicarbonyl compounds in keto-enol form, $\alpha, \beta, \gamma, \delta$-unsaturated aldehydes/ ketones, and/or unsaturated dicarbonyles [105]. In summary, infrared spectroscopy can be exploited to identify six discrete (small) molecules along with five key classes of newly formed molecules carrying the carbonyl group. 


\subsubsection{GAS PHASE - PI-ReTOF-MS}

The FTIR data alone cannot identify individual molecules carrying the carbonyl functional group simply because the group frequencies, for instance saturated aldehydes and ketones, overlap significantly. Next, we utilized the complementary, PI-ReTOF-MS technique to identify individual organic molecules carrying the carbonyl group based on their mass-to-charge ratios, the sublimation temperatures, and how these mass-to-charge ratios shift upon isotope labeling. The use of isotopically labeled ices $\left[\mathrm{CD}_{4}-\mathrm{CO}, \mathrm{CD}_{4}-{ }^{13} \mathrm{CO}, \mathrm{CH}_{4}-\mathrm{C}^{18} \mathrm{O}\right]$ and irradiating, we assign those mass-to-charge ratios to carbonyl-carrying molecules based upon the observed shift of, for instance, $2 \mathrm{u}$ (replacing $\mathrm{CO}$ by $\mathrm{C}^{18} \mathrm{O}$ ) or $1 \mathrm{u}$ (replacing $\mathrm{CO}$ by ${ }^{13} \mathrm{CO}$ ). By comparing isotopically labeled counterparts' sublimation events in all four ices by plotting the sublimation temperatures versus the ion counts and verifying that these species hold identical sublimation profiles allows for further confirmation of the assignments. This protocol identified eleven classes of molecules subliming into the gas phase with masses up to $200 \mathrm{u}$ (Fig. 11a) [29].

Let us focus on the identification of acetaldehyde $\left(\mathrm{CH}_{3} \mathrm{CHO}\right)$. A comparison of the TPD profile at $\mathrm{m} / \mathrm{z}=44$ obtained at a photoionization energy of $10.49 \mathrm{eV}$ (Fig. 12a) demonstrates the unique advantages of PI-ReTOF-MS compared to conventional QMS with electron impact ionization of the molecules (QMS-EI) (Fig. 5) [29]. Signal at $\mathrm{m} / \mathrm{z}=44$ can originate from ionization of carbon dioxide $\left(\mathrm{CO}_{2}\right)$, propane $\left(\mathrm{C}_{3} \mathrm{H}_{8}\right)$, and ethylene oxide/acetaldehyde/vinyl alcohol $\left(\mathrm{C}_{2} \mathrm{H}_{4} \mathrm{O}\right)$. In the case of QMS-EI, all these products can be ionized, making an assignment difficult. However, PI-RETOF-MS resulted in an excellent signal-to-noise ratio of about 150 depicting a bimodal profile peaking at $117 \mathrm{~K}$ and $147 \mathrm{~K}$. With a photon energy of $10.49 \mathrm{eV}$, contributions from carbon dioxide $(\mathrm{IE}=13.78 \mathrm{eV})$ and propane $(\mathrm{IE}=10.94 \mathrm{eV})$ [134] can be neglected because their ionization energies are higher than the energy of the $10.49 \mathrm{eV}$ photon. Therefore, the observed signal at $\mathrm{m} / \mathrm{z}=44$ may only be due to the $\mathrm{C}_{2} \mathrm{H}_{4} \mathrm{O}$ isomers. Ethylene oxide $\left(\mathrm{c}-\mathrm{C}_{2} \mathrm{H}_{4} \mathrm{O}\right)$, has an ionization energy of $10.56 \mathrm{eV}$ [134], which is also higher than the energy of the photon exploited for the photoionization $(10.49 \mathrm{eV})$; hence, ethylene oxide will not contribute any signal at $\mathrm{m} / \mathrm{z}=44$ either. However, acetaldehyde and vinyl alcohol hold ionization energies of $10.23 \mathrm{eV}$ and $9.33 \mathrm{eV}$ [134], respectively, which are lower than $10.49 \mathrm{eV}$. Considering that the signal detected by PI-ReTOF-MS at $\mathrm{m} / \mathrm{z}=44$ clearly shows two pronounced peaks and that two specific isomers, acetaldehyde $\left(\mathrm{CH}_{3} \mathrm{CHO}\right)$ and vinyl alcohol $\left(\mathrm{CH}_{2} \mathrm{CHOH}\right)$, can be ionized, the data suggest that both isomers are formed in the radiation 
exposure of methane - carbon monoxide ices with energetic electrons. To discriminate these isomers, we are exploiting $9.80 \mathrm{eV}$ photons to ionize the subliming molecules (Fig. 12a). At $10.49 \mathrm{eV}$, both acetaldehyde $\left(\mathrm{CH}_{3} \mathrm{CHO} ; \mathrm{IE}=10.23 \mathrm{eV}\right)$ and vinyl alcohol $\left(\mathrm{C}_{2} \mathrm{H}_{3} \mathrm{OH}\right.$; IE $=9.33$ eV) can be ionized. At a photon energy of $9.80 \mathrm{eV}$, only vinyl alcohol can be ionized. A comparison of the TPD profiles taken at $10.49 \mathrm{eV}$ and $9.80 \mathrm{eV}$ clearly shows that the peaks at $117 \mathrm{~K}$ and $147 \mathrm{~K}$ can be assigned to acetaldehyde and vinyl alcohol, respectively, demonstrating that structural isomers of complex organic molecules can be discriminated exploiting tunable VUV photoionization of the subliming molecules. Note that the sublimation profiles were also confirmed with the isotopically substituted counterparts in the irradiated $\mathrm{CD}_{4}-\mathrm{CO}, \mathrm{CD}_{4}-{ }^{13} \mathrm{CO}$, and $\mathrm{CH}_{4}-\mathrm{C}^{18} \mathrm{O}$ ices via their isotope shifts.

\subsubsection{CORRELATION OF FTIR AND PI-ReTOF-MS}

Finally, we would like to correlate the infrared spectra and the development of the absorptions of the carbonyl-bearing molecules as the irradiated samples are warmed up to $300 \mathrm{~K}$ with the PI-ReTOF-MS data. To demonstrate the advantages of the PI-ReTOF-MS data, we are focusing on aldehydes first. Here, in the infrared spectra, the carbonyl stretches of aldehydes are visible up to $300 \mathrm{~K}$. The sublimation profile of higher mass saturated aldehydes (and ketones) such as $\mathrm{C}_{5} \mathrm{H}_{10} \mathrm{O}$ and $\mathrm{C}_{6} \mathrm{H}_{12} \mathrm{O}$ as monitored via PI-ReTOF-MS via their parent ions also exhibit ion counts up to $300 \mathrm{~K}$. More specifically, the infrared intensity of the $1727 \mathrm{~cm}^{-1}$ carrier tentatively assigned as acetaldehyde is observable up to $270 \mathrm{~K}$ (Fig. 13). However, considering the sublimation profile of PI-ReTOF-MS signal at $\mathrm{m} / \mathrm{z}=44$ (Fig. 12a), the sublimation of acetaldehyde is complete at $150 \mathrm{~K}$. Therefore, the remaining intensity of the $1727 \mathrm{~cm}^{-1}$ band beyond $150 \mathrm{~K}$ has contributions from higher order aldehydes as demonstrated by the PI-ReTOFMS data, e.g. $\mathrm{C}_{3} \mathrm{H}_{6} \mathrm{O}(\mathrm{m} / \mathrm{z}=58), \mathrm{C}_{4} \mathrm{H}_{8} \mathrm{O}(\mathrm{m} / \mathrm{z}=72), \mathrm{C}_{5} \mathrm{H}_{10} \mathrm{O}(\mathrm{m} / \mathrm{z}=86)$, and $\mathrm{C}_{6} \mathrm{H}_{12} \mathrm{O}(\mathrm{m} / \mathrm{z}=100)$ (Fig. 13a, Fig. 14a/b) [29]. These findings demonstrate that FTIR spectroscopy alone might lead to an educational 'suggestion' of the $1727 \mathrm{~cm}^{-1}$ feature to be acetaldehyde, but the PI-ReTOFMS data present compelling evidence that the $1727 \mathrm{~cm}^{-1}$ band along with the remaining deconvoluted features are the result of multiple complex organic molecules (here: aldehydes) and not of acetaldehyde alone. Therefore, a careful correlation and verification of suggestions of complex organic molecules by infrared spectroscopy must be conducted via PI-ReTOF-MS. 


\subsection{THE CO - $\mathrm{NH}_{3}$ SYSTEM \\ 4.2.1. CONDENSED PHASE - FTIR}

Several new absorption features emerged during the exposure to energetic electrons (Fig. 4b) [135]. These could be securely attributed to the formation of six discrete species: the formyl radical (HCO) $\left(1851 \mathrm{~cm}^{-1}, v_{3}\right)$, formaldehyde $\left(\mathrm{H}_{2} \mathrm{CO}\right)\left(1740 \mathrm{~cm}^{-1}, v_{2} ; 1510 \mathrm{~cm}^{-1}, v_{3}\right)[136,137]$, the isocyanate ion $\left(\mathrm{OCN}^{-}\right)\left(2150 \mathrm{~cm}^{-1}, v_{3}\right)$ [136,137], the ammonium cation $\left(\mathrm{NH}_{4}^{+}\right)\left(1505 \mathrm{~cm}^{-1}\right.$, $\left.v_{4}\right)[136,138]$ and - at higher doses - carbon suboxide $\left(\mathrm{C}_{3} \mathrm{O}_{2}\right)\left(2192 \mathrm{~cm}^{-1}, v_{1} ; 2242 \mathrm{~cm}^{-1}, v_{3} ; 2399\right.$ $\left.\mathrm{cm}^{-1}, v_{2}+v_{4}\right)[139,140]$, diimide $\left(\mathrm{NNH}_{2}\right)\left(2805 \mathrm{~cm}^{-1}, \mathrm{~N}-\mathrm{H}\right.$ stretch), and tentatively cis-diazene $\left(\right.$ cis- $\left.\mathrm{N}_{2} \mathrm{H}_{2}\right)\left(3066 \mathrm{~cm}^{-1}, v_{1} ; 2963 \mathrm{~cm}^{-1}, v_{5}\right)$ [141,142] (Table 2b). Absorptions of hydrazine $\left(\mathrm{N}_{2} \mathrm{H}_{4}\right)$ are obscured by ammonia and hence only emerged after ammonia has sublimed at $140 \mathrm{~K}$ (890 $\mathrm{cm}^{-1}, v_{6} ; 1072 \mathrm{~cm}^{-1}, v_{12} ; 1136 \mathrm{~cm}^{-1}, v_{5} ; 1606 \mathrm{~cm}^{-1}, v_{3} ; 3194 \mathrm{~cm}^{-1}, v_{2} ; 3300 \mathrm{~cm}^{-1}, v_{1} ; 3319 \mathrm{~cm}^{-1}$, $\left.v_{8} ;\right)[142,143]$. The amidogen radical $\left(\mathrm{NH}_{2}\right)$, which represents the analog of the methyl radical $\left(\mathrm{CH}_{3}\right)$, could only be detected in pure ammonia ices irradiated with energetic electrons [144]. Finally, we should note two broad absorption features in the range of 1750 to $1660 \mathrm{~cm}^{-1}$ and 1200 to $1050 \mathrm{~cm}^{-1}$, which can be attributed to the carbonyl stretches like the $1695 \mathrm{~cm}^{-1}\left(v_{4}\right)$ absorption of formamide $\left(\mathrm{HCONH}_{2}\right)$ [137,145,146], which is red-shifted compared to the carbonyl stretch in acetaldehyde, and - NH bending and rocking modes of amines and imides such as from the $-\mathrm{NH}_{2}$ moiety of urea $\left(\mathrm{CO}\left(\mathrm{NH}_{2}\right)_{2}, v_{5}\right)$ and/or from the cis- and trans-formylhydrazine isomers $\left(\mathrm{HCON}_{2} \mathrm{H}_{3}\right)$, respectively. Therefore, the infrared data support the secure assignment of six individual molecules during the radiation exposure and also of the carbonyl functional group - possibly an amide moiety. 


\subsubsection{GAS PHASE - PI-ReTOF-MS}

Since the infrared data alone cannot assign the individual molecules leading to the carbonyl absorptions, we once again exploit the PI-ReTOF-MS technique to assign individual organic molecules carrying the carbonyl group based on their mass-to-charge ratios and their sublimation temperatures (Fig. 11b). After ammonia desorbs at $110 \mathrm{~K}$, multiple species with higher mass-to-charge ratios are also observed. Most notably, at $\mathrm{m} / \mathrm{z}=32, \mathrm{~m} / \mathrm{z}=45$ and $\mathrm{m} / \mathrm{z}=60$, ions which can be attributed to $\mathrm{N}_{2} \mathrm{H}_{4}{ }^{+}$, $\mathrm{CONH}_{3}{ }^{+}$and $\mathrm{CON}_{2} \mathrm{H}_{4}{ }^{+}$, respectively, were probed. These can be correlated with hydrazine $\left(\mathrm{N}_{2} \mathrm{H}_{4}\right)$, formamide $\left(\mathrm{HCONH}_{2}\right)$ as well as urea $\left(\mathrm{CO}\left(\mathrm{NH}_{2}\right)_{2}\right)$ and/or cis-and trans formylhydrazine $\left(\mathrm{HCON}_{2} \mathrm{H}_{3}\right)$, respectively. Considering the ionization energies of formamide $\left(\mathrm{HCONH}_{2}, 10.16 \mathrm{eV}\right)$, urea $\left(\mathrm{CO}\left(\mathrm{NH}_{2}\right)_{2} ; 9.62 \mathrm{eV}\right)$ and the cis-and trans formylhydrazine isomers $\left(\mathrm{HCON}_{2} \mathrm{H}_{3}\right.$; cis- $8.22 \mathrm{eV}$ and trans- $\left.8.58 \mathrm{eV}\right)$ [134, 135], two separate experiments have to be conducted to discriminate these isomers. Photoionization at $10.49 \mathrm{eV}$ ionizes both urea $(\mathrm{m} / \mathrm{z}=60)$ and formylhydrazine $(\mathrm{m} / \mathrm{z}=60)$ along with formamide $(\mathrm{m} / \mathrm{z}=45)$ (Fig. 12b) [135]. However, $9.0 \mathrm{eV}$ photons only ionize cis-/trans-formylhydrazine. Figure 12b portrays the TPD profiles recorded at $\mathrm{m} / \mathrm{z}=45$ and $\mathrm{m} / \mathrm{z}=60$ with photoionization energies of $10.49 \mathrm{eV}$ and $9.00 \mathrm{eV}$. These ions can be attributed to $\mathrm{CONH}_{3}{ }^{+}$and $\mathrm{CON}_{2} \mathrm{H}_{4}{ }^{+}$, respectively, which originate from singly ionized formamide $\left(\mathrm{HCONH}_{2}\right)$ as well as urea $\left(\mathrm{CO}\left(\mathrm{NH}_{2}\right)_{2}\right)$ and/or cis-and trans formylhydrazine $\left(\mathrm{HCON}_{2} \mathrm{H}_{3}\right)$, respectively. To discriminate if signal at $\mathrm{m} / \mathrm{z}=60$ originates from urea and/or formylhydrazine, it is necessary to reduce the photon energy below the ionization energy of urea, but to stay above the ionization energy of formylhydrazine. As the photo-ionization energy is lowered to $9.00 \mathrm{eV}$, signal at $\mathrm{m} / \mathrm{z}=45$ and 60 disappears completely. Therefore, the lack of ion counts at $\mathrm{m} / \mathrm{z}=60$ demonstrates that only urea is formed, but not the formylhydrazine isomer. Considering the molecular weight of urea which is higher by $15 \mathrm{u}$ ($\mathrm{NH}-$ ) compared to formamide, the earlier onset of the sublimation of formamide of $180 \mathrm{~K}$ compared to $200 \mathrm{~K}$ for urea is reasonable; this effect is also amplified when comparing the ion counts at $\mathrm{m} / \mathrm{z}=45$ and 60 peaking at $210 \mathrm{~K}$ and $270 \mathrm{~K}$, respectively. To summarize, the PIReTOF-MS data provide compelling evidence on the formation of two molecules containing a peptide bond: formamide $\left(\mathrm{HCONH}_{2}\right)$ and urea $\left(\mathrm{CO}\left(\mathrm{NH}_{2}\right)_{2}\right)$.

\subsubsection{CORRELATION OF FTIR AND PI-ReTOF-MS}




\section{HE CO - $\mathrm{CH}_{3} \mathrm{OH}$ SYSTEM}

During the irradiation of the methanol $\left(\mathrm{CH}_{3} \mathrm{OH}\right)$ - carbon monoxide $(\mathrm{CO})$ ices, multiple new absorption features emerged, which could be connected to the synthesis of six individual molecules (Fig. 4c) [28]. The hydroxymethyl radical $\left(\mathrm{CH}_{2} \mathrm{OH}\right)$ was detected via the $v_{4}$ absorption band at $1193 \mathrm{~cm}^{-1}[39,40,147]$ (Table 2c). Formaldehyde $\left(\mathrm{H}_{2} \mathrm{CO}\right)$ was observed via the $v_{2}, v_{3}$, and $v_{4}$ absorption bands at $1249 \mathrm{~cm}^{-1}, 1497 \mathrm{~cm}^{-1}$, and $1726 \mathrm{~cm}^{-1}[39,40,148]$. The formation of formyl radical (HCO) was attributed via the $v_{3}$ fundamental at $1842 \mathrm{~cm}^{-1}[39,40,148,149]$. Methane $\left(\mathrm{CH}_{4}\right)$ was detected via the $v_{4}$ fundamental at $1303 \mathrm{~cm}^{-1}[85,128]$. The formation of carbon monoxide (CO) was confirmed via the $v_{1}$ fundamental at $2135 \mathrm{~cm}^{-1}$ [113]. In addition, carbon dioxide $\left(\mathrm{CO}_{2}\right)$ was detected via the $v_{3}$ mode at $2342 \mathrm{~cm}^{-1}[113,150]$. Besides these 'simple' molecules formed during the irradiation, multiple new infrared absorption features were also observed. The new absorption features connected to the carbonyl functional group in the 1800$1600 \mathrm{~cm}^{-1}$ region are very broad implying the presence of multiple carriers. The deconvoluted absorption bands of carbonyl functional group in the $1800-1600 \mathrm{~cm}^{-1}$ region proposed at least three carriers. Here, glycolaldehyde $\mathrm{HOCH}_{2} \mathrm{CHO}$ was attributed to the $1743 \mathrm{~cm}^{-1}$ band; however, this absorption may also have contributions from saturated aldehydes such as propanal $\left(\mathrm{CH}_{3} \mathrm{CH}_{2} \mathrm{CHO}\right)$ and butanal $\left(\mathrm{C}_{3} \mathrm{H}_{7} \mathrm{CHO}\right)$ [39,40,130,131,151,152]. Formaldehyde $\left(\mathrm{H}_{2} \mathrm{CO}\right)$ leads to an absorption at $1726 \mathrm{~cm}^{-1}[39,40,153-155]$, which could also have intensity from acetaldehyde $\left(\mathrm{CH}_{3} \mathrm{CHO}\right)[43,156]$, whereas methyl formate $\left(\mathrm{HCOOCH}_{3}\right)$ was proposed to account for the $1714 \mathrm{~cm}^{-1}$ position $[39,40,154,155]$. A second band at $1062 \mathrm{~cm}^{-1}$ can be assigned to the $v_{7}$ fundamental of glycolaldehyde [39,151,152,154,155]. Note that ethylene glycol $\left(\mathrm{HOCH}_{2}\right.$ 

spectroscopy alone cannot untangle the contribution of each molecule to this absorption. The assignment of these absorptions was also confirmed via their isotopic shifts in irradiated binary mixed ices consisting of $\mathrm{CD}_{3} \mathrm{OD}-\mathrm{CO},{ }^{13} \mathrm{CH}_{3} \mathrm{OH}-\mathrm{CO}, \mathrm{CH}_{3}{ }^{18} \mathrm{OH}-\mathrm{CO}, \mathrm{CD}_{3} \mathrm{OD}-{ }^{13} \mathrm{CO}, \mathrm{CH}_{3}{ }^{18} \mathrm{OH}-$ $\mathrm{C}^{18} \mathrm{O}$ and $\mathrm{CH}_{3} \mathrm{OH}-\mathrm{C}^{18} \mathrm{O}$. Note that ketene $\left(\mathrm{H}_{2} \mathrm{CCO}\right)$ could only be identified in the isotopically labelled ices since in the methanol - carbon monoxide system, the most intense fundamental of ketene overlaps with the stretching mode of carbon monoxide [119]. In summary, we wish to stress once more that FTIR spectroscopy can only elucidate particular vibrational modes of complex organics synthesized in situ of bulk ices from exposure to ionizing radiation and very rarely, actual molecular isomers. Consequently, we turn our attention to a more sensitive technique allowing for the identification of individual molecules via their molecular formula and ionization energy, temperature program desorption coupled with photoionization reflectron timeof-flight mass spectrometry (PI-ReTOF-MS).

\subsubsection{GAS PHASE - PI-ReTOF-MS}

Following the in situ identification of small molecules and vibrational modes of more complex organics as described above, we employed the use of temperature programmed desorption (TPD) spectroscopy to monitor the products sublimating via PI-ReTOF-MS. Molecules up to $150 \mathrm{u}$ are observed (Fig. 11c) [28], which cannot be identified via traditional infrared spectroscopy. This observation alone implies the presence of rich and complex chemistry in the methanol - carbon monoxide ices. In detail, these studies firmly identified the following complex organic molecules based on their ionization energies, their shifts upon isotopic substitution, and/or calibration of the sublimation profiled in doped methanol - carbon monoxide ices (Table 2c; Fig. 12c): ketene $\left(\mathrm{H}_{2} \mathrm{CCO}\right)$, acetaldehyde $\left(\mathrm{HCOCH}_{3}\right)$, vinyl alcohol $\left(\mathrm{CH}_{2} \mathrm{CHOH}\right)$, ethanol $\left(\mathrm{C}_{2} \mathrm{H}_{5} \mathrm{OH}\right)$, dimethyl ether $\left(\mathrm{CH}_{3} \mathrm{OCH}_{3}\right)$, glyoxal $(\mathrm{HCOHCO})$, glycolaldehyde $\left(\mathrm{HOCH}_{2} \mathrm{CHO}\right)$, ethene-1,2-diol ( $\mathrm{HOCHCHOH})$, ethylene glycol $\left(\mathrm{HOCH}_{2} \mathrm{CH}_{2} \mathrm{OH}\right)$, methoxy methanol $\left(\mathrm{CH}_{3} \mathrm{OCH} \mathrm{H}_{2} \mathrm{OH}\right)$, and glycerol $\left(\mathrm{H}_{2} \mathrm{OHCHOHCH}{ }_{2} \mathrm{OH}\right)$ [28]. The identification of glycerol - the central molecular building block of lipids such as glycerol phospholipids and phosphoglycerides, which are the key components of all cell membranes - presented a particular challenge. HeadGordon et al. [157] determined that upon photoionization, glycerol will not only ionize to the 

producing the $\mathrm{C}_{3} \mathrm{H}_{6} \mathrm{O}_{2}{ }^{+}(\mathrm{m} / \mathrm{z}=74), \mathrm{C}_{2} \mathrm{H}_{6} \mathrm{O}_{2}{ }^{+}(\mathrm{m} / \mathrm{z}=62), \mathrm{C}_{2} \mathrm{H}_{5} \mathrm{O}_{2}{ }^{+}(\mathrm{m} / \mathrm{z}=61), \mathrm{C}_{2} \mathrm{H}_{4} \mathrm{O}_{2}{ }^{+}(\mathrm{m} / \mathrm{z}=$ $60), \mathrm{C}_{2} \mathrm{H}_{5} \mathrm{O}^{+}(\mathrm{m} / \mathrm{z}=45)$, and $\mathrm{C}_{2} \mathrm{H}_{4} \mathrm{O}^{+}(\mathrm{m} / \mathrm{z}=44)$ fragment ions with the parent ion formed at levels of less than a few percent of the total ion counts. To verify the formation of glycerol in the ice experiments, it was necessary to extract the sublimation profile of glycerol not only by monitoring parent ion $\left(\mathrm{C}_{3} \mathrm{H}_{8} \mathrm{O}_{3}{ }^{+} ; \mathrm{m} / \mathrm{z}=92\right)$, but also of the fragment ions versus the temperature. In doing so, we could integrate the TPD profiles and match the relative intensities with literature data thus assigning glycerol for the first time [26]. Finally, several classes of molecules yet to be specifically identified were observed sublimating from the irradiated ices: $\mathrm{C}_{3} \mathrm{H}_{(\mathrm{x}=4,6,8)} \mathrm{O}$, $\mathrm{C}_{4} \mathrm{H}_{(\mathrm{x}=8,10)} \mathrm{O}, \mathrm{C}_{3} \mathrm{H}_{(\mathrm{x}=4,6,8)} \mathrm{O}_{2}, \mathrm{C}_{4} \mathrm{H}_{(\mathrm{x}=6,8)} \mathrm{O}_{2}, \mathrm{C}_{3} \mathrm{H}_{(\mathrm{x}=4,6)} \mathrm{O}_{3}, \mathrm{C}_{4} \mathrm{H}_{8} \mathrm{O}_{3}, \mathrm{C}_{4} \mathrm{H}_{(\mathrm{x}=4,6,8)} \mathrm{O}_{4}, \mathrm{C}_{5} \mathrm{H}_{(\mathrm{x}=6,8)} \mathrm{O}_{4}$ and $\mathrm{C}_{5} \mathrm{H}_{(\mathrm{x}=6,8)} \mathrm{O}_{5}$ (Fig. 14c) [28]. The last groups of molecules containing four to five oxygen atoms include a astrobiologically important class of sugars relevant in RNA, phospholipids and energy storage. Experiments are currently being designed to elucidate their chemical structure.

\subsubsection{CORRELATION OF FTIR AND PI-ReTOF-MS}

As an example, we would like to examine the sublimation of glycolaldehyde monitored via online and in situ infrared spectroscopy and PI-ReTOF-MS (Figs. 12c and 13c) [28]. Figure 13c depicts a comparison of the infrared absorption band at $1743 \mathrm{~cm}^{-1}$, originating from glycolaldehyde and from saturated aldehydes such as propanal $\left(\mathrm{CH}_{3} \mathrm{CH}_{2} \mathrm{CHO}\right)$ and butanal $\left(\mathrm{C}_{3} \mathrm{H}_{7} \mathrm{CHO}\right)$, as a function of temperature with the derived sublimation profile at $\mathrm{m} / \mathrm{z}=60$ recorded using PI-ReTOF-MS. In the irradiated methanol-carbon monoxide ices, $1.6 \pm 0.1 \times 10^{15}$ glycolaldehyde molecules were produced. During the warm-up phase, at $50 \mathrm{~K}$ the production of glycolaldehyde increased to $1.9 \pm 0.2 \times 10^{15}$ molecules. Additionally, the abundance of formyl radical shows a maximum of $1.6 \pm 0.2 \times 10^{15}$ molecules immediately following irradiation where upon it remains stable until $25 \mathrm{~K}$ and subsequently cannot be detected beyond $50 \mathrm{~K}$. Within the range of $25 \mathrm{~K}$ to $50 \mathrm{~K}$, the formyl radical shows a decrease in abundance by $1.6 \pm 0.2 \times 10^{15}$ molecules. Here, the abundance of glycolaldehyde is increased by $2.0 \pm 0.2 \times 10^{14}$ molecules. The above evidence suggest that during the warm up phase, trapped radicals diffuse and exhibit additional thermal chemistry and resulting in the formation of additional glycolaldehyde molecules. After the phase change of methanol ices at $110-125 \mathrm{~K}$, the abundance of glycolaldehyde 
continually decreased until $150 \mathrm{~K}\left(6.3 \pm 0.6 \times 10^{14}\right.$ molecules $)$. After that, the band declines quickly and finally becomes untraceable beyond $195 \mathrm{~K}$.

\subsection{THE CO - $\mathrm{C}_{2} \mathrm{H}_{4} \mathrm{SYSTEM}$ \\ 4.4.1. CONDENSED PHASE - FTIR}

The processing of the binary ice resulted in multiple novel absorption bands (Fig. $4 \mathrm{~d}$; Table 2d). Distinct features corresponding to six small molecules: acetylene $\left(\mathrm{C}_{2} \mathrm{H}_{2}\right)\left(3300 \mathrm{~cm}^{-1}\right.$, $\left.v_{3} ; 758 \mathrm{~cm}^{-1}, v_{5}\right)[158,159]$, ethane $\left(\mathrm{C}_{2} \mathrm{H}_{6}\right)\left(2880 \mathrm{~cm}^{-1}, v_{5}\right)[158,160,161]$, butene $\left(\mathrm{C}_{4} \mathrm{H}_{8}\right)(1642$ $\left.\mathrm{cm}^{-1}, v_{4}\right)[158,161]$, butane $\left(\mathrm{C}_{4} \mathrm{H}_{10}\right)\left(1464 \mathrm{~cm}^{-1}, v_{14}\right)[158,160,161]$, the formyl radical (HCO) $\left(1845 \mathrm{~cm}^{-1}, v_{3}\right)[35,43]$, and carbon dioxide $\left(\mathrm{CO}_{2}\right)\left(2340 \mathrm{~cm}^{-1}, v_{6}\right)[150,162]$ were detected and confirmed via their isotopic shifts in $\mathrm{C}^{18} \mathrm{O}-\mathrm{C}_{2} \mathrm{D}_{4}$ ices [163].

Also, a broad feature corresponding to carbonyl stretching was observed. This feature has contributions from multiple distinct molecules and/or isomers as discussed in section 4.1.1. and was deconvoluted revealing three distinct peaks. These groups correspond to saturated carbonyl compounds $\left(1722 \mathrm{~cm}^{-1}\right)$ [131], $\alpha, \beta$-unsaturated aldehydes/ketones $\left(1696 \mathrm{~cm}^{-1}\right)$ [105], and $\alpha, \beta$ dicarbonyl compounds in keto-enol form, $\alpha, \beta, \gamma, \delta$-unsaturated aldehydes/ ketones, and/or unsaturated dicarbonyles $\left(1680 \mathrm{~cm}^{-1}\right)$ [105]. Several of these new infrared features can be tentatively assigned to the three $\mathrm{C}_{3} \mathrm{H}_{4} \mathrm{O}$ isomers: propenal $\left(\mathrm{CH}_{2} \mathrm{HCHCO}\right)\left(1696 \mathrm{~cm}^{-1}, v_{5}\right)$ [164], cyclopropanone $\left(\mathrm{c}-\mathrm{C}_{3} \mathrm{H}_{4} \mathrm{O}\right)\left(1822 \mathrm{~cm}^{-1}, v_{2}\right)$ [165], and methylketene $\left(\mathrm{CH}_{3} \mathrm{CHCO}\right)\left(2136 \mathrm{~cm}^{-1}, v_{4}\right)$ [166]. However, each of these infrared bands may be obscured by other molecules as the $v_{5}$ fundamental of propenal is in the region of all unsaturated carbonyl compounds, the $v_{2}$ fundamental of cyclopropanone occurs in the same region that the hydroxycarbonyl (HOCO) radical appears $[167,168]$, and the $v_{4}$ fundamental of methylketene overlaps with the infrared stretching of the initial reactant carbon monoxide $\left(2138 \mathrm{~cm}^{-1}, v_{1}\right)$ [113]. Therefore, utilizing FTIR alone only six specific (small) molecules were able to be determined, but more complex molecules were only able to be tentatively assigned and three classes of carbonyl type molecules were identified.

\subsubsection{GAS PHASE - PI-ReTOF-MS}

As the FTIR data was only able to tentatively identify complex molecules contributing to several of the new post irradiation features including the carbonyl stretching region, it is necessary to utilize complimentary techniques to further investigate the system. This was done 

other this problem can be circumvented by the use of isotopic labeling as well as comparison of unique sublimation events (TPD profiles). Furthermore, the tuning of the energy of the photon used in the photoionization of the molecule even allows for the discrimination between isomers if their ionization energies are separated by greater than $0.01 \mathrm{eV}$. This method identified subliming molecules with masses at least to $150 \mathrm{u}$ (Fig. 11d) [163].

In the binary carbon monoxide $(\mathrm{CO})$ - ethylene $\left(\mathrm{C}_{2} \mathrm{H}_{4}\right)$ irradiated ice the focus is on the $\mathrm{C}_{3} \mathrm{H}_{4} \mathrm{O}$ isomers propenal $\left(\mathrm{CH}_{2} \mathrm{HCHCO}, \mathrm{IE}=10.10 \mathrm{eV}\right)$, cyclopropanone $\left(\mathrm{c}-\mathrm{C}_{3} \mathrm{H}_{4} \mathrm{O}, \mathrm{IE}=9.10\right.$ $\mathrm{eV})$, and methylketene $\left(\mathrm{CH}_{3} \mathrm{CHCO}, 8.95 \mathrm{eV}\right)$ [134]. As with all isomers they will have the same mass-to-charge ratio and therefore tunable photoionization is a way to uniquely identify specific isomers. However, the hydrocarbon butene also has the same mass-to-charge ratio and therefore isotopic labeling was also employed to create $\mathrm{C}_{3} \mathrm{H}_{4} \mathrm{O}$ isomers with a unique mass-to-charge ratio $(\mathrm{m} / \mathrm{z}=62)$. These isomer's ionization energies are sufficiently separated and therefore experiments with photoionization energies at $10.49 \mathrm{eV}, 9.60 \mathrm{eV}$, and $9.00 \mathrm{eV}$ were performed to specifically identify which isomers were present as $10.49 \mathrm{eV}$ will ionize all three isomer, $9.60 \mathrm{eV}$ will only ionize cyclopropanone $\left(\mathrm{c}-\mathrm{C}_{3} \mathrm{H}_{4} \mathrm{O}, \mathrm{IE}=9.10 \mathrm{eV}\right)$ and/or methylketene $\left(\mathrm{CH}_{3} \mathrm{CHCO}, 8.95\right.$ $\mathrm{eV}$ ), and $9.00 \mathrm{eV}$ will solely ionize methylketene but neither of the other isomers.

Each of these experiments resulted in signal at $\mathrm{m} / \mathrm{z}=62$ or $\mathrm{m} / \mathrm{z}=56$ in isotopic and nonisotopic ices, respectively (Fig. 12d) [163]. The $10.49 \mathrm{eV}$ experiment showed a signal with two distinct peaks corresponding to two separate sublimation events and most likely corresponding to separate isomers. The $9.60 \mathrm{eV}$ experiment showed a signal matching the sublimation profile from $90 \mathrm{~K}$ to $133 \mathrm{~K}$ of the first peak provided in the initial experiment at $10.49 \mathrm{eV}$ and proves that there are multiple isomers being produced in the experiment corresponding the to the $\mathrm{C}_{3} \mathrm{H}_{4} \mathrm{O}$ isomers. Also, a TPD calibration experiment at $10.49 \mathrm{eV}$ of $\mathrm{CO}-\mathrm{C}_{2} \mathrm{H}_{4}$ ice doped with $1 \%$ propenal showed a sublimation event at $109 \mathrm{~K}$ to $128 \mathrm{~K}$ similar to the second peak of the irradiated $\mathrm{C}^{18} \mathrm{O}-\mathrm{C}_{2} \mathrm{D}_{4}$ irradiated ice experiment second peak $(\mathrm{m} / \mathrm{z}=62)$ from $120 \mathrm{~K}$ to $173 \mathrm{~K}$, which after subtraction of the peak area detected in the $9.60 \mathrm{eV}$ experiment shows a sublimation onset temperature of the second $10.49 \mathrm{eV} \mathrm{m} / \mathrm{a}=62$ peak to be at $109 \mathrm{~K}$. Finally, the $9.00 \mathrm{eV}$ experiment also showed a smaller signal from $91 \mathrm{~K}$ to $121 \mathrm{~K}$ as well and thus to determine if two or all three isomers were being produced ionization cross-sections were used to determine the 
amount of each isomer across experiments. This showed it is most likely that all three isomers propenal $\left(\mathrm{CH}_{2} \mathrm{HCHCO}\right)$, cyclopropanone $\left(\mathrm{c}-\mathrm{C}_{3} \mathrm{H}_{4} \mathrm{O}\right)$, and methylketene $\left(\mathrm{CH}_{3} \mathrm{CHCO}\right)$ were produced in this system with a ratio of 5.6:1.4:1.0, respectively.

\subsubsection{CORRELATION OF FTIR AND PI-ReTOF-MS}

The correlation of the FTIR data with PI-ReTOF-MS during TPD shows that the carbonyl stretching is not only related to the $\mathrm{C}_{3} \mathrm{H}_{4} \mathrm{O}$ isomers because even after their corresponding massto-charge signal is no longer detected in the ReTOF, the FTIR data still shows an infrared band corresponding to carbonyl stretching, which is observable up to temperatures greater than $200 \mathrm{~K}$ (Fig. 13d) [163]. The possibility of larger carbonyl containing molecules contributing to this infrared stretching is substantiated by masses as high as $150 \mathrm{u}$ being detected in the ReTOF as the temperature approaches $300 \mathrm{~K}$. Also, there is an observable decrease in the carbonyl stretching when the corresponding $\mathrm{C}_{3} \mathrm{H}_{4} \mathrm{O}$ isomers mass-to-charge is detected using PI-ReTOFMS showing that although FTIR cannot give direct confirmation of complex molecules it is a very useful complimentary tool to RI-ReTOF-MS and can provide further evidence for initially tentative assignments in analogue ice systems.

The methylketene isomer detected in the $9.00 \mathrm{eV}$ experiments was initially obscured by the stretching mode of the carbon monoxide reactant, but even after this has sublimed there are alternative ketenes such as ketene $\left(\mathrm{C}_{2} \mathrm{H}_{2} \mathrm{O}\right)$ and larger ketenes $\left(\mathrm{C}_{4} \mathrm{H}_{6} \mathrm{O}\right)$ [119] that have infrared stretching in this region. This shows that even though an overlapping species has been removed (sublimed) there is still no new information present in the infrared and only when detected using the PI-ReTOF-MS protocol can this information is correlated to changes in the FTIR data to provide compelling evidence that a specific molecule(s) existed initially within the processed ice.

\section{SUMMARY}

Exploiting reflectron time of flight mass spectrometry coupled with single photon ionization of the subliming molecules (PI-ReTOF-MS) during the temperature programmed desorption (TPD) and combining these data with on line and in situ infrared spectroscopy (FTIR) along with solving the coupled differential equations of the temporal evolution of the newly formed molecules, a versatile experimental approach has been established to elucidate the formation pathways of complex organic molecules in interstellar analog ices upon interaction with ionizing 
Second, the suprathermal hydrogen atoms generated in these processes were found to react at ultralow temperatures of $5 \mathrm{~K}$ with carbon monoxide $(\mathrm{CO})$ via addition forming the formyl radical (HCO) (reaction (5)), which can be stabilized in the matrix by phonon interaction. It is important to note that suprathermal hydrogen atoms can easily overcome the entrance barrier to addition of $0.09 \mathrm{eV}[173,174]$. The experimental data and the kinetic fittings suggest that if the formyl radical (HCO) is in neighborhood to a doublet radical such as methyl, amino, hydroxyl, and/or hydroxymethyl/methoxy and if both radical reactants are in a favorable geometry, these radicals 

$\left(\mathrm{HCOCH}_{2} \mathrm{OH}\right)$, and formic acid methylester $\left(\mathrm{HCOOCH}_{3}\right)$ - carrying the carbonyl moiety as a central building block (Fig. 15). Generally spoken, the formyl radical (HCO) has the ability to recombine with any doublet radical (R) (reaction (6)). Therefore even hydrocarbons more complex than methane such as the $\mathrm{C} 2$ hydrocarbons acetylene $\left(\mathrm{C}_{2} \mathrm{H}_{2}\right)$, ethylene $\left(\mathrm{C}_{2} \mathrm{H}_{4}\right)$, and ethane $\left(\mathrm{C}_{2} \mathrm{H}_{6}\right)$ can undergo decomposition via atomic hydrogen loss leading to the ethynyl $(\mathrm{CCH})$, vinyl $\left(\mathrm{C}_{2} \mathrm{H}_{3}\right)$, and ethyl $\left(\mathrm{C}_{2} \mathrm{H}_{5}\right)$ radical. Once more, the suprathermal hydrogen atom adds to carbon monoxide via equation (5) forming the formyl radical (HCO) which then recombined with the hydrocarbon radicals leading to propynal $(\mathrm{HCCHCO})$, propenal $\left(\mathrm{C}_{2} \mathrm{H}_{3} \mathrm{HCO}\right)$, and propanal $\left(\mathrm{C}_{2} \mathrm{H}_{5} \mathrm{HCO}\right)$, respectively (Fig. 15). It shall be stressed that these complex organic molecules are formed at $5 \mathrm{~K}$ within the ices as the result of non-equilibrium chemistry initiated by suprathermal hydrogen atoms followed by barrier-less radical-radical recombination [71,85,175]. Most importantly, in case of chemically non-equivalent hydrogen atoms in the reactants such as in methanol, two distinct radicals - the hydroxymethyl and methoxy radical form distinct structural isomers upon recombination with the formyl radical: glycolaldehyde $\left(\mathrm{HCOCH}_{2} \mathrm{OH}\right)$ and formic acid methylester $\left(\mathrm{HCOOCH}_{3}\right)$ [39] thus providing isomer selective formation pathways of complex organic molecules in interstellar ices. Note that the third $\mathrm{C}_{2} \mathrm{H}_{4} \mathrm{O}_{2}$ isomer - acetic acid $\left(\mathrm{CH}_{3} \mathrm{COOH}\right)$ - was not formed in the experiments reported here; however, this isomer was synthesized in irradiated methane - carbon dioxide ices at ultralow temperatures as a radical-radical recombination product of the hydroxylcarbonyl (HOCO) with the methyl $\left(\mathrm{CH}_{3}\right)$ radical [35]. These (ice composition dependent) isomer-specific reaction pathways leading to complex organic molecules inside the ices demonstrate the necessity to incorporate non-equilibrium processing of low temperature interstellar ices involving suprathermal reactants in future astrochemical models on the formation of complex organic molecules. To a certain degree, the low temperature matrix also stores reactive radicals such as formyl (HCO) and hydroxymethyl $\left(\mathrm{CH}_{2} \mathrm{OH}\right)$. Upon annealing of the ices, these radicals can diffuse and might recombine. Based on our results, this thermal route represents less prominent pathways leading to complex organic molecules within the processed ices.

Third, the doublet radicals formed in the decomposition of methane $\left(\mathrm{CH}_{4}\right)$, ammonia $\left(\mathrm{NH}_{3}\right)$, water $\left(\mathrm{H}_{2} \mathrm{O}\right)$, and methanol $\left(\mathrm{CH}_{3} \mathrm{OH}\right)$ - methyl $\left(\mathrm{CH}_{3}\right)$, amidogen $\left(\mathrm{NH}_{2}\right)$, hydroxyl $(\mathrm{OH})$, and 
hydroxylmethyl/methoxy $\left(\mathrm{CH}_{2} \mathrm{OH} / \mathrm{CH}_{3} \mathrm{O}\right)$ - were also found to recombine within the low temperature ices during the radiation exposure leading to ethane $\left(\mathrm{C}_{2} \mathrm{H}_{6}\right)$, hydrazine $\left(\mathrm{N}_{2} \mathrm{H}_{4}\right)$, hydrogen peroxide $\left(\mathrm{H}_{2} \mathrm{O}_{2}\right)$, and ethylene glycol $\left(\mathrm{HOCH}_{2} \mathrm{CH}_{2} \mathrm{OH}\right)$ along with methoxy methanol $\left(\mathrm{CH}_{3} \mathrm{OCH}_{2} \mathrm{OH}\right)$ (Fig. 15). A detailed kinetic fitting of the data combined with isotopic substitution experiments demonstrated that a radiolysis of these species lead, for instance, to ethylene $\left(\mathrm{C}_{2} \mathrm{H}_{4}\right)$ and acetylene $\left(\mathrm{C}_{2} \mathrm{H}_{2}\right)$ as well as diimide and diazene $\left(\mathrm{NNH}_{2}\right.$ and $\left.\mathrm{HNNH}\right)$. A radical-radical recombination pathway via recombination of two formyl species was also found to lead to the formation of glyoxal ( $\mathrm{HCOHCO})$.

Finally, ReTOF-MS coupled with tunable photoionization (PI) has been established as a valuable tool to detect complex organic molecules and in particular their structural isomers such as acetaldehyde $\left(\mathrm{HCOCH}_{3}\right)$ and vinyl alcohol $\left(\mathrm{C}_{2} \mathrm{H}_{3} \mathrm{OH}\right)$, which cannot be assigned with traditional analytical tools such as FTIR and QMS interfaced to space simulation chambers. Infrared spectroscopy only allows an identification of very few simple molecules in irradiated and/or photolyzed ices - typically less than ten. On the other hand, PI-ReTOF-MS reveals that the processing of astrophysically relevant ices can lead to more multifaceted mixtures of complex organic molecules - as demonstrated here in terms of carbonyl-bearing specie. These species can reach molecular weights of up to $200 \mathrm{u}$ and cover multiple classes of complex organic molecules as compiled in Figures 12-15 with up to 70 molecules identified in individual irradiation experiments on line and in situ. These novel techniques are needed to confidently assign detections in laboratory ice analog experiments as the molecules of interest become more complex also from the viewpoint of future astronomical detections in the age of the Atacama Large Millimeter/submillimeter Array (ALMA). Specifically, structural isomers can serve as a unique system to understand non-equilibrium versus thermal reaction pathways. Also, they can be utilized as tracers of low temperature non-equilibrium chemistry within interstellar ices. The increasing detection of new and more complex organic molecules in space continues to grow including biorelevant molecules connected to the Origins of Life theme - and will rely on future advances in hard core physical chemistry laboratory experiments.

\section{Acknowledgements}


The authors would like to thank the W. M. Keck Foundation for financing the experimental setup. M.F. acknowledges funding for a Postdoctoral Fellowship from the Deutsche Forschungsgemeinschaft (FO 941/1). RIK and MJA thanks the US National Science Foundation (AST-1505502) for support.

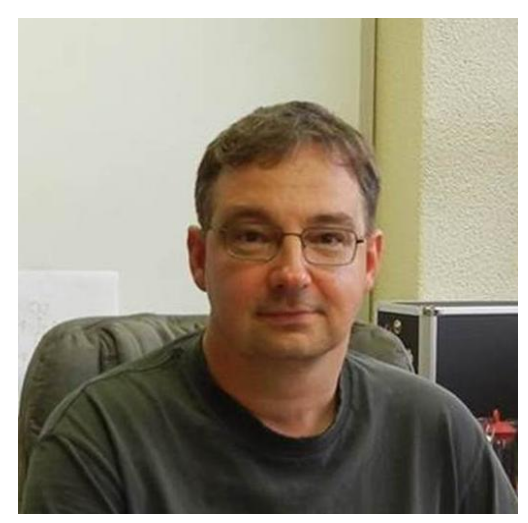

\section{Biography R.I. Kaiser}

Ralf I. Kaiser received his Ph.D. in Chemistry from the University of Münster (Germany) in condensed phase physical chemistry (astrochemistry, nuclear chemistry) in 1994. He conducted postdoctoral work on the gas phase formation of astrochemically relevant molecules at UC Berkeley (Department of Chemistry). From 1997-2000 he received a fellowship from the German Research Council (DFG) to perform his Habilitation at the Department of Physics (University of Chemnitz, Germany) and Institute of Atomic and Molecular Sciences (Academia Sinica, Taiwan). He joined the Department of Chemistry at the University of Hawaii at Manoa in 2002 where he is currently a Professor of Chemistry and Director of the W.M. Keck Research Laboratory in Astrochemistry. Ralf I. Kaiser has been elected Fellow of the Royal Astronomical Society (UK) (2005), Royal Society of Chemistry (UK) (2011), American Physical Society (2012), American Association for the Advancement of Science (AAAS) (2013), and the Institute of Physics (UK) (2014).

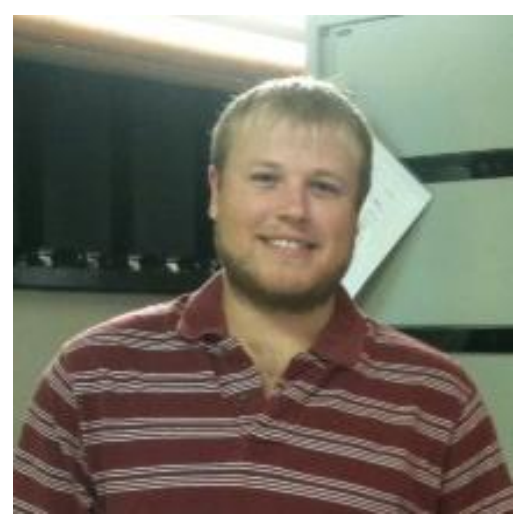

Biography M.J. Abplanalp 
Matthew J. Abplanalp received his B.S. in Chemistry from the University of Pittsburgh at Bradford (2012). He is currently working on his Ph.D. in Physical Chemistry at the University of Hawaii at Manoa in the Department of Chemistry at the W.M. Keck Research Laboratory in Astrochemistry. He is investigating the formation of complex organic molecules in interstellar ices.

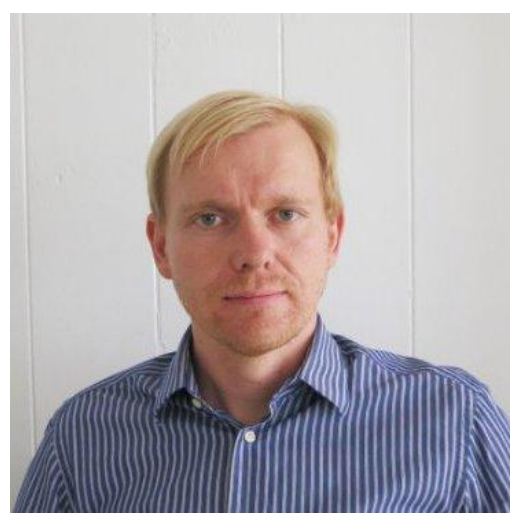

\section{Biography Marko Förstel}

Marko Förstel received his PhD in Physics from the Technical University Berlin in 2012. His dissertation in the Hergenhahn group at the Max-Planck Institute for Plasma Physics dealt with non-local autoionization processes in rare gas clusters. He is currently a postdoctoral fellow of the Deutsche Forschungsgemeinschaft (DFG) at the University of Hawaii at Manoa in the Department of Chemistry at the W.M. Keck Research Laboratory in Astrochemistry. His main research goal is to understand the formation of the biorelevant molecules carrying the peptide bond in astrophysically relevant environments. 


\section{Tables}

Table 1: Detected interstellar and cometary ice constituents and abundances [54] (YSO = young stellar objects).

\begin{tabular}{|c|c|c|}
\hline molecule & abundance toward YSOs* & abundance in comets* \\
\hline $\mathrm{H}_{2} \mathrm{O}$ & 100 & 100 \\
\hline $\mathrm{CH}_{3} \mathrm{OH}$ & $<3-31$ & $0.2-7$ \\
\hline $\mathrm{CO}$ & $3-26$ & $0.4-30$ \\
\hline $\mathrm{CO}_{2}$ & $11-27$ & $4-30$ \\
\hline $\mathrm{CH}_{4}$ & $1-3$ & $0.4-1.6$ \\
\hline $\mathrm{H}_{2} \mathrm{CO}$ & $2-7$ & $0.11-1.0$ \\
\hline $\mathrm{NH}_{3}$ & 7 & $0.2-1.4$ \\
\hline $\mathrm{OCS}^{-}$ & $0.03-0.16$ & $0.1-0.4$ \\
\hline $\mathrm{OCN}^{-}$ & $0.1-1.9$ & - \\
\hline
\end{tabular}

*relative to the water ice. 
Table 2a: Infrared absorptions features before and after irradiation of $\mathrm{CO}-\mathrm{CH}_{4}$ ice at $5.5 \mathrm{~K}$.

\begin{tabular}{|c|c|c|c|c|}
\hline before irradiation $\left(\mathrm{cm}^{-1}\right)$ & new features $\left(\mathrm{cm}^{-1}\right)$ & assignment & carrier & reference \\
\hline 4534 & & $v_{2}+v_{3}\left(\mathrm{CH}_{4}\right)$ & combination & {$[128]$} \\
\hline 4302 & & $v_{3}+v_{4}\left(\mathrm{CH}_{4}\right)$ & combination & [128] \\
\hline 4248 & & $2 v_{1}(\mathrm{CO})$ & overtone & [176] \\
\hline \multirow[t]{4}{*}{4204} & & $v_{1}+v_{4}\left(\mathrm{CH}_{4}\right)$ & combination & [128] \\
\hline & 3253 & $v_{3}\left(\mathrm{C}_{2} \mathrm{H}_{2}\right)$ & CH str. & {$[85,128]$} \\
\hline & 3151 & $v_{3}\left(\mathrm{CH}_{3}\right)$ & CH str. & {$[43,85]$} \\
\hline & 3093 & $v_{9}\left(\mathrm{C}_{2} \mathrm{H}_{4}\right)$ & $\mathrm{CH}_{2}$ asym. str. & [128] \\
\hline \multirow[t]{5}{*}{3011} & & $v_{3}\left(\mathrm{CH}_{4}\right)$ & deg. str. & {$[85,128]$} \\
\hline & 2978 & $v_{10}\left(\mathrm{C}_{2} \mathrm{H}_{6}\right)$ & $\mathrm{CH}_{3}$ deg. str. & {$[85,128]$} \\
\hline & 2962 & $v_{1}\left(\mathrm{C}_{2} \mathrm{H}_{6}\right)$ & $\mathrm{CH}_{3}$ sym. str & {$[85,128]$} \\
\hline & 2943 & $v_{8}+v_{11}\left(\mathrm{C}_{2} \mathrm{H}_{6}\right)$ & combination & {$[85,128]$} \\
\hline & 2920 & $v_{8}+v_{11}\left(\mathrm{C}_{2} \mathrm{H}_{6}\right)$ & combination & {$[85,128]$} \\
\hline \multirow[t]{2}{*}{2905} & & $v_{1}\left(\mathrm{CH}_{4}\right)$ & sym. str. & {$[85,128]$} \\
\hline & 2885 & $v_{5}\left(\mathrm{C}_{2} \mathrm{H}_{6}\right)$ & $\mathrm{CH}_{3}$ sym str. & {$[85,128]$} \\
\hline \multirow[t]{2}{*}{2818} & & $v_{2}+v_{4}\left(\mathrm{CH}_{4}\right)$ & combination & {$[85,128]$} \\
\hline & 2748 & $v_{2}+v_{6}\left(\mathrm{C}_{2} \mathrm{H}_{6}\right)$ & combination & {$[85,128]$} \\
\hline \multirow[t]{3}{*}{2595} & & $2 v_{4}\left(\mathrm{CH}_{4}\right)$ & overtone & {$[85,128]$} \\
\hline & 2341 & $v_{6}\left(\mathrm{CO}_{2}\right)$ & CO asym. str. & [113] \\
\hline & 2276 & $v_{6}\left({ }^{13} \mathrm{CO}_{2}\right)$ & CO asym. str. & [113] \\
\hline 2137 & & $v_{1}(\mathrm{CO})$ & CO str. & {$[113,176]$} \\
\hline \multirow[t]{11}{*}{2090} & & $v_{1}\left({ }^{13} \mathrm{CO}\right)$ & CO str. & {$[176]$} \\
\hline & 1853 & $v_{2}(\mathrm{HCO})$ & CO str. & [43] \\
\hline & 1746 & & CO str. & {$[130,131]$} \\
\hline & 1727 & $v_{4}\left(\mathrm{CH}_{3} \mathrm{CHO}\right)$ & CO str. & {$[43]$} \\
\hline & 1717 & $\mathrm{~b}$ & CO str. & {$[132,133]$} \\
\hline & 1701 & & $\mathrm{CO}$ str. & {$[105]$} \\
\hline & 1660 & d & CO str. & {$[105]$} \\
\hline & 1466 & $v_{11}\left(\mathrm{C}_{2} \mathrm{H}_{6}\right)$ & $\mathrm{CH}_{3}$ deform & {$[85,128]$} \\
\hline & 1427 & $v_{12}\left(\mathrm{CH}_{3} \mathrm{CHO}\right)$ & $\mathrm{CH}_{3}$ deform. & {$[43]$} \\
\hline & 1373 & $v_{6}\left(\mathrm{C}_{2} \mathrm{H}_{6}\right)$ & $\mathrm{CH}_{3}$ sym deform. & {$[85,128]$} \\
\hline & 1350 & $v_{7}\left(\mathrm{CH}_{3} \mathrm{CHO}\right)$ & $\mathrm{CH}_{3}$ deform. & {$[43]$} \\
\hline \multirow[t]{4}{*}{1302} & & $v_{4}\left(\mathrm{CH}_{4}\right)$ & deg. str. & {$[85,128]$} \\
\hline & 1120 & $v_{8}\left(\mathrm{CH}_{3} \mathrm{CHO}\right)$ & $\mathrm{CH}_{3}$ deform. & {$[43]$} \\
\hline & 1091 & $v_{2}(\mathrm{HCO})$ & bending & [43] \\
\hline & 613 & $v_{2}\left(\mathrm{CH}_{3}\right)$ & out of plane & {$[85,128]$} \\
\hline
\end{tabular}

${ }^{\mathrm{a}} \mathrm{RC}(=\mathrm{O}) \mathrm{H}$ saturated aliphatic aldehydes

' saturated ketones RCOR'

${ }^{c} \alpha, \beta$-unsaturated aldehydes/ketones

${ }^{\mathrm{d}} \alpha, \beta, \gamma, \delta$-unsaturated aldehydes/ketones and/or $\alpha, \beta$-dicarbonyl compounds in keto-enol form 
Table 2b: Infrared absorptions features before and after irradiation of $\mathrm{CO}-\mathrm{NH}_{3}$ ice at $5.5 \mathrm{~K}$.

\begin{tabular}{|l|l|l|l|}
\hline before irradiation $\left(\mathrm{cm}^{-1}\right)$ & new features $\left(\mathrm{cm}^{-1}\right)$ & assignment & reference \\
\hline 1087 & & $v_{2}\left(\mathrm{NH}_{3}\right)$ & {$[177]$} \\
\hline & 1050 to 1150 & $\mathrm{NNH}$ bend $/ \mathrm{NH}$ rocks & {$[178]$} \\
\hline & 1150 & $v_{5}\left(\mathrm{CO}\left(\mathrm{NH}_{2}\right)_{2}\right)$ & {$[179]$} \\
\hline & & $v_{1}(\mathrm{CO})$ & {$[180]$} \\
\hline & 1510 & $v_{3}\left(\mathrm{H}_{2} \mathrm{CO}\right)$ & {$[43,136,137,181]$} \\
\hline 1633 & 1505 & $v_{4}\left(\mathrm{NH}_{4}{ }^{+}\right)$ & {$[136,138]$} \\
\hline & & $v_{4}\left(\mathrm{NH}_{3}\right)$ & {$[177]$} \\
\hline & 1660 to 1750 & $\mathrm{X}-\mathrm{C}=\mathrm{O}$ str. & {$[136]$} \\
\hline & 1695 & $v_{2}\left(\mathrm{HCONH}_{2}\right)$ & {$[136,182]$} \\
\hline & 1740 & $v_{4}\left(\mathrm{H}_{2} \mathrm{CO}\right)$ & {$[43,136,137,181]$} \\
\hline 3200 & 2150 & $v_{1}\left(\mathrm{OCN}^{-}\right)$ & {$[136,137,183]$} \\
\hline 3370 & & $v_{1}\left(\mathrm{NH}_{3}\right)$ & {$[177]$} \\
\hline 4480 & & $v_{3}\left(\mathrm{NH}_{3}\right)$ & {$[177]$} \\
\hline
\end{tabular}




\begin{tabular}{|c|c|c|c|}
\hline before irradiation $\left(\mathrm{cm}^{-1}\right)$ & new features $\left(\mathrm{cm}^{-1}\right)$ & assignments $[39,40,184]$ & carrier \\
\hline 4399 & & $v_{2} / v_{9}+v_{4} / v_{6} / v_{10}\left(\mathrm{CH}_{3} \mathrm{OH}\right)$ & combination \\
\hline 4274 & & $v_{2} / v_{9}+v_{4}\left(\mathrm{CH}_{3} \mathrm{OH}\right)$ & combination \\
\hline 4247 & & $2 v_{1}(\mathrm{CO})$ & overtone \\
\hline 4021 & & $v_{2} / v_{9}+v_{8}\left(\mathrm{CH}_{3} \mathrm{OH}\right)$ & combination \\
\hline 3987 & & $v_{2} / v_{9}+v_{8}\left(\mathrm{CH}_{3} \mathrm{OH}\right)$ & combination \\
\hline 3623 & & $v_{1}\left(\mathrm{CH}_{3} \mathrm{OH} \cdots \mathrm{CO}\right)$ & fundamental \\
\hline $3462,3383,3271,3123$ & & $v_{1}\left(\mathrm{CH}_{3} \mathrm{OH}\right)$ & fundamental \\
\hline 2985 & & $v_{2}\left(\mathrm{CH}_{3} \mathrm{OH}\right)$ & fundamental \\
\hline 2956 & & $v_{9}\left(\mathrm{CH}_{3} \mathrm{OH}\right)$ & fundamental \\
\hline 2925 & & $\begin{array}{l}v_{4}+v_{5} / v_{4}+v_{10} / v_{5}+v_{10} / 2 v_{4} \\
/ 2 v_{10} / 2 v_{5}\left(\mathrm{CH}_{3} \mathrm{OH}\right)\end{array}$ & $\begin{array}{l}\text { combination / } \\
\text { overtone }\end{array}$ \\
\hline 2828 & & $v_{3} / 2 v_{6}\left(\mathrm{CH}_{3} \mathrm{OH}\right)$ & $\begin{array}{l}\text { fundamental / } \\
\text { overtone }\end{array}$ \\
\hline 2604 & & $\begin{array}{l}v_{4}+v_{11} / v_{7}+v_{4} / v_{6} / v_{10} \\
\left(\mathrm{CH}_{3} \mathrm{OH}\right)\end{array}$ & combination \\
\hline 2524 & & $v_{6}+v_{11}\left(\mathrm{CH}_{3} \mathrm{OH}\right)$ & combination \\
\hline \multirow[t]{2}{*}{2438} & & $v_{6}+v_{8}\left(\mathrm{CH}_{3} \mathrm{OH}\right)$ & combination \\
\hline & 2342 & $v_{3}\left(\mathrm{CO}_{2}\right)$ & fundamental \\
\hline 2226 & & $2 v_{11} / 2 v_{7}\left(\mathrm{CH}_{3} \mathrm{OH}\right)$ & overtone \\
\hline 2135 & & $v_{1}(\mathrm{CO})$ & fundamental \\
\hline 2089 & & $v_{1}\left({ }^{13} \mathrm{CO} / \mathrm{C}^{18} \mathrm{O}\right)$ & fundamental \\
\hline \multirow[t]{6}{*}{2047} & & $2 v_{8}\left(\mathrm{CH}_{3} \mathrm{OH}\right)$ & overtone \\
\hline & 1842 & $v_{3}(\mathrm{HCO})$ & fundamental \\
\hline & 1743 & $v_{14}\left(\mathrm{HOCH}_{2} \mathrm{CHO}\right)$ & fundamental \\
\hline & 1726 & $v_{4}\left(\mathrm{H}_{2} \mathrm{CO}\right)$ & fundamental \\
\hline & 1697 & $2 v_{6}\left(\mathrm{HOCH}_{2} \mathrm{CHO}\right)$ & overtone \\
\hline & 1497 & $v_{3}\left(\mathrm{H}_{2} \mathrm{CO}\right)$ & combination \\
\hline 1475 & & $v_{4}\left(\mathrm{CH}_{3} \mathrm{OH}\right)$ & fundamental \\
\hline 1461 & & $v_{10}\left(\mathrm{CH}_{3} \mathrm{OH}\right)$ & fundamental \\
\hline 1445 & & $v_{5}\left(\mathrm{CH}_{3} \mathrm{OH}\right)$ & fundamental \\
\hline \multirow[t]{4}{*}{1421} & & $v_{6}\left(\mathrm{CH}_{3} \mathrm{OH}\right)$ & fundamental \\
\hline & 1303 & $v_{4}\left(\mathrm{CH}_{4}\right)$ & fundamental \\
\hline & 1249 & & \\
\hline & 1193 & $v_{4}\left(\mathrm{CH}_{2} \mathrm{OH}\right)$ & fundamental \\
\hline \multirow[t]{3}{*}{$1153,1129,1117$} & & $v_{7}\left(\mathrm{CH}_{3} \mathrm{OH}\right)$ & fundamental \\
\hline & 1094 & $v_{9}\left(\mathrm{HOCH}_{2} \mathrm{CH}_{2} \mathrm{OH}\right)$ & fundamental \\
\hline & 1062 & $v_{7}\left(\mathrm{HOCH}_{2} \mathrm{CHO}\right)$ & fundamental \\
\hline 1039 & & $v_{11}\left(\mathrm{CH}_{3} \mathrm{OH}\right)$ & fundamental \\
\hline 1028 & & $v_{8}\left(\mathrm{CH}_{3} \mathrm{OH}\right)$ & fundamental \\
\hline
\end{tabular}


Table 2d: Infrared absorptions features before and after irradiation of $\mathrm{CO}-\mathrm{C}_{2} \mathrm{H}_{4}$ ice at $5.5 \mathrm{~K}$.

\begin{tabular}{|c|c|c|c|c|}
\hline $\begin{array}{l}\text { before irradiation } \\
\left(\mathrm{cm}^{-1}\right)\end{array}$ & $\begin{array}{l}\text { new features } \\
\left(\mathrm{cm}^{-1}\right)\end{array}$ & assignment & carrier & reference \\
\hline $\begin{array}{l}4746,4710,4578, \\
4500,4426,4396, \\
4310,4275,4192\end{array}$ & & $\begin{array}{l}v_{9}+2 v_{6}, v_{9}+v_{2}, v_{11}+v_{2}, v_{5} \\
+v_{12}, v_{9}+v_{3}, v_{9}+v_{6}, v_{11}+ \\
v_{3}, v_{11}+v_{6} \quad\left(C_{2} H_{4}\right)\end{array}$ & overtones/combinations & {$[185,186]$} \\
\hline \multirow[t]{3}{*}{4248} & & $2 v_{1}(\mathrm{CO})$ & overtone & {$[43,162,176]$} \\
\hline & 3300 & $v_{3}\left(\mathrm{C}_{2} \mathrm{H}_{2}\right)$ & $\mathrm{CH}$ stretch & {$[158,187]$} \\
\hline & 3245 & $v_{3}\left(\mathrm{C}_{2} \mathrm{H}_{2}\right)$ & $\mathrm{CH}$ stretch & {$[85,158,160]$} \\
\hline 3092 & & $v_{9}\left(\mathrm{C}_{2} \mathrm{H}_{4}\right)$ & $\mathrm{CH}_{2}$ asymmetric stretch & {$[161,186-188]$} \\
\hline 3069 & & $v_{2}+v_{12}\left(\mathrm{C}_{2} \mathrm{H}_{4}\right)$ & combination & {$[186,188]$} \\
\hline \multirow[t]{9}{*}{2977} & & $v_{11}\left(\mathrm{C}_{2} \mathrm{H}_{4}\right)$ & $\mathrm{CH}_{2}$ symmetric stretch & [186-189] \\
\hline & 2965 & $\begin{array}{l}v_{12}\left(\mathrm{C}_{4} \mathrm{H}_{10}\right) / v_{10}\left(\mathrm{C}_{2} \mathrm{H}_{6}\right) / v_{16} \\
\left(\mathrm{C}_{4} \mathrm{H}_{8}\right)\end{array}$ & $\mathrm{CH}_{3}$ stretch & $\begin{array}{l}{[35,128,158,16} \\
0,190,191]\end{array}$ \\
\hline & 2940 & $\begin{array}{l}v_{8}+v_{11}\left(\mathrm{C}_{2} \mathrm{H}_{6}\right) / v_{12}\left(\mathrm{C}_{4} \mathrm{H}_{10}\right) / \\
v_{23}\left(\mathrm{C}_{4} \mathrm{H}_{8}\right)\end{array}$ & $\begin{array}{l}\text { combination/ } / \mathrm{CH}_{2} \\
\text { asymmetric stretch }\end{array}$ & $\begin{array}{l}{[128,160,161,1} \\
91]\end{array}$ \\
\hline & 2918 & $v_{8}+v_{11}\left(C_{2} H_{6}\right)$ & combination & {$[158,160,190]$} \\
\hline & 2880 & $v_{5}\left(\mathrm{C}_{2} \mathrm{H}_{6}\right) / v_{28}\left(\mathrm{C}_{4} \mathrm{H}_{10}\right)$ & $\mathrm{CH}_{3}$ stretch & $\begin{array}{l}{[158,160,161,1} \\
90]\end{array}$ \\
\hline & 2862 & $v_{29}\left(\mathrm{C}_{4} \mathrm{H}_{10}\right)$ & $\mathrm{CH}_{2}$ symmetric stretch & {$[158,187,190]$} \\
\hline & 2832 & $v_{6}+v_{11}\left(\mathrm{C}_{2} \mathrm{H}_{6}\right)$ & combination & {$[160]$} \\
\hline & 2740 & $v_{2}+v_{6}\left(\mathrm{C}_{2} \mathrm{H}_{6}\right)$ & combination & {$[158,160]$} \\
\hline & 2340 & $v_{6}\left(\mathrm{CO}_{2}\right)$ & $\mathrm{CO}$ asymmetric stretch & {$[162,176]$} \\
\hline 2138 & & $v_{1}(\mathrm{CO})$ & CO stretch & {$[43,162,176]$} \\
\hline 2090 & & $v_{1}\left({ }^{13} \mathrm{CO}\right)$ & CO stretch & {$[43,162,176]$} \\
\hline 2087 & & $v_{1}\left(\mathrm{C}^{18} \mathrm{O}\right)$ & CO stretch & {$[162,176]$} \\
\hline 2043 & & $v_{1}\left({ }^{13} \mathrm{C}^{18} \mathrm{O}\right)$ & CO stretch & {$[162]$} \\
\hline 1965 & & $v_{4}+v_{8}\left(\mathrm{C}_{2} \mathrm{H}_{4}\right)$ & combination & {$[160]$} \\
\hline \multirow[t]{7}{*}{1899} & & $v_{7}+v_{8}\left(\mathrm{C}_{2} \mathrm{H}_{4}\right)$ & combination & {$[160]$} \\
\hline & 1845 & $v_{3}(\mathrm{HCO})$ & $\mathrm{CO}$ stretch & {$[35,43]$} \\
\hline & 1823 & $v_{2}(\mathrm{HOCO}) / v_{2}\left(\mathrm{c}-\mathrm{C}_{3} \mathrm{H}_{4} \mathrm{O}\right)$ & CO stretch & {$[35,165]$} \\
\hline & 1722 & $\mathrm{a}$ & CO stretch & {$[29,43,192]$} \\
\hline & 1696 & $\mathrm{~b}$ & $\mathrm{CO}$ stretch & [29] \\
\hline & 1680 & c & $\mathrm{CO}$ stretch & {$[29]$} \\
\hline & 1642 & $v_{4}\left(\mathrm{C}_{4} \mathrm{H}_{8}\right)$ & $\mathrm{C}=\mathrm{C}$ stretch & {$[158,161]$} \\
\hline \multirow[t]{2}{*}{1619} & & $v_{2}\left(\mathrm{C}_{2} \mathrm{H}_{4}\right)$ & $\mathrm{C}=\mathrm{C}$ stretch & {$[43,187,188]$} \\
\hline & 1464 & $\begin{array}{l}v_{11}\left(\mathrm{C}_{2} \mathrm{H}_{6}\right) / v_{14}, v_{30}, v_{31} \\
\left(\mathrm{C}_{4} \mathrm{H}_{10}\right)\end{array}$ & $\mathrm{CH}_{3}$ bend & $\begin{array}{l}{[35,158,160,16} \\
1]\end{array}$ \\
\hline \multirow[t]{2}{*}{1439} & & $v_{12}\left(\mathrm{C}_{2} \mathrm{H}_{4}\right)$ & $\mathrm{CH}_{2}$ scissor & {$[43,186-188]$} \\
\hline & 1377 & $v_{6}\left(\mathrm{C}_{2} \mathrm{H}_{6}\right) / v_{32}\left(\mathrm{C}_{4} \mathrm{H}_{10}\right)$ & & {$[85,160,161]$} \\
\hline 1339 & & $v_{3}\left(\mathrm{C}_{2} \mathrm{H}_{4}\right)$ & $\mathrm{CH}_{2}$ scissor & {$[43,187,188]$} \\
\hline 1224 & & $\mathrm{v}_{6}\left(\mathrm{C}_{2} \mathrm{H}_{4}\right)$ & $\mathrm{CH}_{2}$ rock & {$[43,187,188]$} \\
\hline 953 & & $v_{7}\left(\mathrm{C}_{2} \mathrm{H}_{4}\right)$ & $\mathrm{CH}_{2}$ wag & {$[43,186-189]$} \\
\hline \multirow[t]{2}{*}{823} & & $v_{10}\left(\mathrm{C}_{2} \mathrm{H}_{4}\right)$ & $\mathrm{CH}_{2}$ rock & {$[43,187,188]$} \\
\hline & 758 & $v_{5}\left(\mathrm{C}_{2} \mathrm{H}_{2}\right)$ & $\mathrm{CCH}$ bend & {$[159,187]$} \\
\hline
\end{tabular}

${ }^{\mathrm{a}} \mathrm{RC}(=\mathrm{O}) \mathrm{H}$ saturated aliphatic aldehydes

${ }^{\mathrm{b}} \mathrm{R}_{1} \mathrm{R}_{2} \mathrm{C}=\mathrm{CR}_{3}-\mathrm{CH}=\mathrm{O}$ or $\mathrm{RC} \equiv \mathrm{C}-\mathrm{CH}=\mathrm{O} \quad \alpha, \beta$-unsaturated aldehydes (carbonyl) and $\mathrm{R}_{1} \mathrm{R}_{2} \mathrm{C}=\mathrm{CR} \mathrm{R}_{3}-\mathrm{C}(=\mathrm{O}) \mathrm{R}_{4}\left(\mathrm{R}_{4} \neq \mathrm{H}\right)$ or $\mathrm{R}_{1} \mathrm{C} \equiv \mathrm{C}-\mathrm{C}(=\mathrm{O}) \mathrm{R}_{2}\left(\mathrm{R}_{2} \neq \mathrm{H}\right) \alpha, \beta$-unsaturated ketones (carbonyl)

${ }^{\mathrm{c}} \mathrm{R}_{1} \mathrm{R}_{2} \mathrm{C}=\mathrm{CR}_{3}-\mathrm{CH}=\mathrm{O}$ or $\mathrm{RC} \equiv \mathrm{C}-\mathrm{CH}=\mathrm{O} \alpha, \beta$-unsaturated aldehydes (carbonyl) and

$\mathrm{R}_{1} \mathrm{R}_{2} \mathrm{C}=\mathrm{CR}_{3}-\mathrm{C}(=\mathrm{O}) \mathrm{R}_{4}\left(\mathrm{R}_{4} \neq \mathrm{H}\right)$ or $\mathrm{R}_{1} \mathrm{C} \equiv \mathrm{C}-\mathrm{C}(=\mathrm{O}) \mathrm{R}_{2}\left(\mathrm{R}_{2} \neq \mathrm{H}\right) \quad \alpha, \beta$-unsaturated ketones (carbonyl), $\mathrm{R}_{2} \mathrm{C}=\mathrm{CH} \mathrm{H}_{2}$ or

$\mathrm{RHC}=\mathrm{CHR}$ disubstituted (trans), $\mathrm{R}_{2} \mathrm{C}=\mathrm{CHR}$ trisubstituted, and $\mathrm{R}_{2} \mathrm{C}=\mathrm{CR}_{2}$ terasubstituted alkenes 


\section{References}

[1] D.C.B. Whittet, A.M. Cook, E. Herbst, J.E. Chiar, S.S. Shenoy, ApJ 2011, 742 (1).

[2] C. Walsh, T.J. Millar, H. Nomura, E. Herbst, S.W. Weaver, Y. Aikawa, J.C. Laas, A.I. Vasyunin, A\&A 2014, 563 (A33).

[3] E. Herbst, AIP Conference Proceedings 2013, 1543 (1).

[4] P. Ehrenfreund, W. Irvine, T. Owen, L. Becker, J. Blank, J. Brucato, L. Colangeli, S. Derenne, A. Dutrey, D. Despois, Astrobiology: Future Perspectives, Springer Science \& Business Media, 2006.

[5] T. Vasyunina, A.I. Vasyunin, E. Herbst, H. Linz, M. Voronkov, T. Britton, I. Zinchenko, F. Schuller, ApJ 2014, 780 (1).

[6] A. Bacmann, V. Taquet, A. Faure, C. Kahane, C. Ceccarelli, A\&A 2012, 541 (L12).

[7] S.B. Charnley, P. Ehrenfreund, Y.J. Kuan, AcSpA 2001, 57 (4).

[8] Y. Aikawa, V. Wakelam, R.T. Garrod, E. Herbst, ApJ 2008, 674 (2).

[9] R.T. Garrod, S.L.W. Weaver, E. Herbst, ApJ 2008, 682 (1).

[10] E. Herbst, E.F. van Dishoeck, Annu. Rev. Astron. Astrophys. 2009, 47 (1).

[11] C. Walsh, E. Herbst, H. Nomura, T.J. Millar, S.W. Weaver, FaDi 2014, 168 (1).

[12] M.H. Moore, R.L. Hudson, R.F. Ferrante, Earth Moon Planets 2003, 92 (1).

[13] M.P. Bernstein, S.A. Sandford, L.J. Allamandola, S. Chang, M.A. Scharberg, ApJ 1995, 454 (1).

[14] P. Modica, P. De Marcellus, D. Baklouti, R. Brunetto, M. Noun, S. Della Negra, L. Le Sergeant d'Hendecourt, EAS Publications Series 2012, 58 (1).

[15] M.S. Gudipati, J.P. Dworkin, X.D.F. Chillier, L.J. Allamandola, ApJ 2003, 583 (1).

[16] F. Duvernay, V. Dufauret, G. Danger, P. Theule, F. Borget, T. Chiavassa, A\&A 2010, 523 (A79).

[17] F.A. van Broekhuizen, J.V. Keane, W.A. Schutte, A\&A 2004, 415 (2).

[18] Y.J. Chen, M. Nuevo, C.C. Chu, Y.G. Fan, T.S. Yih, W.H. Ip, H.S. Fung, C.Y.R. Wu, Adv. Space Res. 2011, 47 (9).

[19] H. Cottin, C. Szopa, M.H. Moore, ApJ 2001, 561 (1).

[20] M.H. Moore, R.F. Ferrante, J.A. Nuth Iii, P\&SS 1996, 44 (9).

[21] S. Jheeta, A. Domaracka, S. Ptasinska, B. Sivaraman, N.J. Mason, CPL 2013, 556.

[22] N.J. Mason, B. Nair, S. Jheeta, E. Szymanska, FaDi 2014, 168 (1).

[23] W. Hagen, L.J. Allamandola, J.M. Greenberg, Astrophys. Space Sci. 1979, 65 (1).

[24] R.I. Kaiser, K. Roessler, ApJ 1997, 475 (1).

[25] B.M. Jones, R.I. Kaiser, JPhChL 2013, 4 (11).

[26] R.I. Kaiser, S. Maity, B.M. Jones, Angew Chem Int Edit 2015, 54 (1).

[27] S. Maity, R.I. Kaiser, B.M. Jones, PCCP 2015, 17 (5).

[28] S. Maity, R.I. Kaiser, B.M. Jones, FaDi 2014, 168 (1).

[29] R.I. Kaiser, S. Maity, B.M. Jones, PCCP 2014, 16 (8).

[30] B.M. Jones, R.I. Kaiser, G. Strazzulla, ApJ 2014, 781 (2).

[31] C.J. Bennett, C.P. Ennis, R.I. Kaiser, ApJ 2014, 782 (2).

[32] W.A. Schutte, P.A. Gerakines, P\&SS 1995, 43 (10-11).

[33] P.A. Gerakines, M.H. Moore, R.L. Hudson, Icar 2004, 170 (1).

[34] M.H. Moore, B. Donn, R. Khanna, M.F. A'Hearn, Icar 1983, 54 (3).

[35] C.J. Bennett, R.I. Kaiser, ApJ 2007, 660.

[36] Y.S. Kim, R.I. Kaiser, ApJ 2010, 725 (1). 
[37] M.H. Moore, R.L. Hudson, P.A. Gerakines, AcSpA 2001, 57 (4).

[38] G.D. McDonald, L.J. Whited, C. DeRuiter, B.N. Khare, A. Patnaik, C. Sagan, Icar 1996, $122(1)$.

[39] C.J. Bennett, R.I. Kaiser, ApJ 2007, 661 (2).

[40] C.J. Bennett, S.-H. Chen, B.-J. Sun, A.H.H. Chang, R.I. Kaiser, ApJ 2007, 660 (2).

[41] Y.S. Kim, R.I. Kaiser, ApJ 2011, 729 (1).

[42] K.I. Öberg, R.T. Garrod, E.F. van Dishoeck, H. Linnartz, A\&A 2009, 504.

[43] C.J. Bennett, C.S. Jamieson, Y. Osamura, R.I. Kaiser, ApJ 2005, 624.

[44] M.H. Moore, R.L. Hudson, Proceedings IAU Colloquium 2005, 1 (231).

[45] C.-W. Lee, J.-K. Kim, E.-S. Moon, Y.C. Minh, H. Kang, ApJ 2009, 697 (1).

[46] M.P. Bernstein, J.P. Dworkin, S.A. Sandford, G.W. Cooper, L.J. Allamandola, Natur 2002, 416 (6879).

[47] G.M. Munoz Caro, U.J. Meierhenrich, W.A. Schutte, B. Barbier, A. Arcones Segovia, H. Rosenbauer, W.H.P. Thiemann, A. Brack, J.M. Greenberg, Natur 2002, 416 (6879).

[48] C. Meinert, J.J. Filippi, P. de Marcellus, L.L. d'Hendecourt, U.J. Meierhenrich, Chempluschem 2012, 77 (3).

[49] P.D. Holtom, C.J. Bennett, Y. Osamura, N.J. Mason, R.I. Kaiser, ApJ 2005, 626 (2).

[50] G. Danger, F.R. Orthous-Daunay, P. de Marcellus, P. Modica, V. Vuitton, F. Duvernay, L. Flandinet, L.L. d'Hendecourt, R. Thissen, T. Chiavassa, GeCoA 2013, 118 (1).

[51] U.L. Meierhenrich, G.M.M. Caro, W.A. Schutte, W.H.P. Thiemann, B. Barbier, A. Brack, Chem. Eur. J. 2005, 11 (17).

[52] R.I. Kaiser, A.M. Stockton, Y.S. Kim, E.C. Jensen, R.A. Mathies, ApJ 2013, 765 (2).

[53] N.B. Gontareva, E.A. Kuzicheva, V.N. Shelegedin, P\&SS 2009, 57 (4).

[54] A.C.A. Boogert, P.A. Gerakines, D.C.B. Whittet, Annu. Rev. Astron. Astrophys. 2015, $53(1)$.

[55] E. Herbst, J.T. Yates, ChRv 2013, 113 (12).

[56] M. Agundez, V. Wakelam, ChRv 2013, 113 (12).

[57] T. Oka, ChRv 2013, 113 (12).

[58] T. Henning, D. Semenov, ChRv 2013, 113 (12).

[59] Y. Aikawa, ChRv 2013, 113 (12).

[60] M.P. Redman, S. Viti, P. Cau, D.A. Williams, MNRAS 2003, 345 (4).

[61] E. Herbst, Chem. Soc. Rev. 2001, 30 (3).

[62] C. Cecchi-Pestellini, J.M.C. Rawlings, S. Viti, D.A. Williams, ApJ 2010, 725 (2).

[63] D.A. Williams, T.W. Hartquist, Acc. Chem. Res. 1999, 32 (4).

[64] D.A. Williams, The Interstellar Medium: An Overview, Springer, 2003.

[65] H.J. Fraser, M.R. McCoustra, D.A. Williams, NRIAG J. Astron. Geophys. 2002, 43 (2).

[66] D.A. Williams, E. Herbst, Surf. Sci. 2002, 500 (1-3).

[67] E. Herbst, PCCP 2014, 16 (8).

[68] G. Vidali, ChRv 2013, 113 (12).

[69] T. Hama, N. Watanabe, ChRv 2013, 113 (12).

[70] P. Ehrenfreund, S.B. Charnley, Annu. Rev. Astron. Astrophys. 2000, 38 (1).

[71] R.I. Kaiser, ChRv 2002, 102 (5).

[72] A. Occhiogrosso, A. Vasyunin, E. Herbst, S. Viti, M.D. Ward, S.D. Price, W.A. Brown, A\&A 2014, 564.

[73] A.I. Vasyunin, E. Herbst, ApJ 2013, 769 (1).

[74] D.N. Friedel, S.L.W. Weaver, Astrophys. J. Suppl. Ser. 2012, 201 (2). 
[75] M. Lattelais, M. Bertin, H. Mokrane, C. Romanzin, X. Michaut, P. Jeseck, J.H. Fillion, H. Chaabouni, E. Congiu, F. Dulieu, S. Baouche, J.L. Lemaire, F. Pauzat, J. Pilme, C. Minot, Y. Ellinger, A\&A 2011, 532 (A12).

[76] S. Kwok, Physics and Chemistry of the Interstellar Medium, University Science Books, 2007.

[77] R. Brown, J. Crofts, P. Godfrey, F. Gardner, B. Robinson, J. Whiteoak, ApJ 1975, 197 (1).

[78] D.M. Mehringer, L.E. Snyder, Y.T. Miao, ApJ 1997, 480 (1).

[79] J.M.C. Rawlings, D.A. Williams, S. Viti, C. Cecchi-Pestellini, W.W. Duley, FaDi 2014, 168.

[80] J.M.C. Rawlings, D.A. Williams, S. Viti, C. Cecchi-Pestellini, W.W. Duley, MNRAS 2013, 430 (1).

[81] I.W. Smith, Low Temperatures and Cold Molecules, Imperial College Press, 2008.

[82] S.B. Charnley, A.G.G.M. Tielens, T.J. Millar, ApJ 1992, 399 (1).

[83] P. Caselli, T.I. Hasegawa, E. Herbst, ApJ 1993, 408 (2).

[84] J.P. Dworkin, S.A. Sandford, M.P. Bernstein, L.J. Allamandola, NASA Conf. Publ. 2002, 1.

[85] R.I. Kaiser, K. Roessler, ApJ 1998, 503 (2).

[86] M. Garozzo, D. Fulvio, Z. Kanuchova, M.E. Palumbo, G. Strazzulla, A\&A 2010, 509 (A67).

[87] S.E. Bisschop, G.W. Fuchs, E.F. van Dishoeck, H. Linnartz, A\&A 2007, 474 (3).

[88] W.D. Geppert, M. Hamberg, R.D. Thomas, F. Osterdahl, F. Hellberg, V. Zhaunerchyk, A. Ehlerding, T.J. Millar, H. Roberts, J. Semaniak, M. af Ugglas, A. Kallberg, A. Simonsson, M. Kaminska, M. Larsson, FaDi 2006, 133.

[89] R.I. Kaiser, G. Eich, A. Gabrysch, K. Roessler, ApJ 1997, 484 (1).

[90] J. Cronin, S. Chang, Organic Matter in Meteorites: Molecular and Isotopic Analyses of the Murchison Meteorite, Springer Netherlands, 1993.

[91] O. Botta, J.L. Bada, P. Ehrenfreund, ACM 2002, 500.

[92] J.E. Elsila, N.P. de Leon, P.R. Buseck, R.N. Zare, GeCoA 2005, 69 (5).

[93] M.K. Spencer, M.R. Hammond, R.N. Zare, PNAS 2008, 105 (47).

[94] L. Remusat, Y. Guan, Y. Wang, J. Eiler, ApJ 2010, 713 (2).

[95] A. Shimoyama, R. Ogasawara, Orig. Life Evol. Biosph. 2002, 32 (2).

[96] K. Ruiz-Mirazo, C. Briones, A. de la Escosura, ChRv 2014, 114 (1).

[97] R.I. Kaiser, A.M. Mebel, CPL 2008, 465 (1).

[98] R.J. Morton, R.I. Kaiser, P\&SS 2003, 51 (6).

[99] J. He, K. Gao, G. Vidali, C.J. Bennett, R.I. Kaiser, ApJ 2010, 721 (2).

[100] C.S. Jamieson, C.J. Bennett, A.M. Mebel, R.I. Kaiser, ApJ 2005, 624 (1).

[101] W. Zheng, D. Jewitt, R.I. Kaiser, ApJ 2006, 639 (1).

[102] W. Zheng, D. Jewitt, R.I. Kaiser, ApJ 2006, 648 (1).

[103] C.S. Jamieson, A.H.H. Chang, R.I. Kaiser, Adv. Space Res. 2009, 43.

[104] W.J. Zheng, Y.S. Kim, R.I. Kaiser, PCCP 2011, 13 (35).

[105] G. Socrates, Infrared and Raman characteristic group frequencies: tables and charts, John Wiley \& Sons, 2004.

[106] C.J. Bennett, Y. Osamura, M.D. Lebar, R.I. Kaiser, ApJ 2005, 634 (1).

[107] L. Zhou, R.I. Kaiser, L.G. Gao, A.H.H. Chang, M.C. Liang, Y.L. Yung, ApJ 2008, 686 (2). 
[108] S. Ioppolo, H.M. Cuppen, E.F. Van Dishoeck, H. Linnartz, MNRAS 2011, 410 (2).

[109] A. Jiménez-Escobar, G.M. Caro, A\&A 2011, 536 (A91).

[110] H.J. Fraser, M.P. Collings, M.R.S. McCoustra, Rev. Sci. Instrum. 2002, 73 (5).

[111] F. Duvernay, A. Rimola, P. Theule, G. Danger, T. Sanchez, T. Chiavassa, PCCP 2014, 16 (44).

[112] R.I. Kaiser, A. Gabrysch, K. Roessler, Rev. Sci. Instrum. 1995, 66 (4).

[113] C.J. Bennett, C. Jamieson, A.M. Mebel, R.I. Kaiser, PCCP 2004, 6 (4).

[114] R.I. Kaiser, P. Jansen, K. Petersen, K. Roessler, Rev. Sci. Instrum. 1995, 66 (11).

[115] P. de Marcellus, C. Meinert, I. Myrgorodska, L. Nahon, T. Buhse, L.L.S. d'Hendecourt, U.J. Meierhenrich, PNAS 2015, 112 (4).

[116] M.P. Callahan, P.A. Gerakines, M.G. Martin, Z. Peeters, R.L. Hudson, Icar 2013, 226 (2).

[117] R.I. Kaiser, K. Roessler, Ann. Geophys. 1992, 10 (3-4).

[118] N. Abou Mrad, F. Duvernay, P. Theulé, T. Chiavassa, G.g. Danger, Anal. Chem. 2014, 86 (16).

[119] S. Maity, R.I. Kaiser, B.M. Jones, ApJ 2014, 789 (1).

[120] C.J. Bennett, S.J. Brotton, B.M. Jones, A.K. Misra, S.K. Sharma, R.I. Kaiser, Anal. Chem. 2013, 85 (12).

[121] R. Hilbig, G. Hilber, A. Lago, B. Wolff, R. Wallenstein, Nonlinear Optics and Applications 1986, 613.

[122] R. Hilbig, R. Wallenstein, IEEE J. Quantum Electron. 1983, 19 (12).

[123] W.A. VonDrasek, S. Okajima, J.P. Hessler, ApOpt 1988, 27 (19).

[124] R.G. Tonkyn, M.G. White, Rev. Sci. Instrum. 1989, 60 (7).

[125] K.I. Öberg, A.C.A. Boogert, K.M. Pontoppidan, S. van den Broek, E.F. van Dishoeck, B. Sandrine, A.B. Geoffrey, I. Neal J. Evans, ApJ 2011, 740 (2).

[126] R.I. Kaiser, G. Eich, A. Gabrysch, K. Roessler, A\&A 1999, 346 (1).

[127] L. Zhou, W. Zheng, R.I. Kaiser, A. Landera, A.M. Mebel, M.C. Liang, Y.L. Yung, ApJ 2010, 718 (2).

[128] C.J. Bennett, C.S. Jamieson, Y. Osumura, R.I. Kaiser, ApJ 2006, 653 (1).

[129] M.H. Moore, R.L. Hudson, Icar 2003, 161 (2).

[130] G.A. Guirgis, B.R. Drew, T.K. Gounev, J.R. Durig, AcSpA 1998, 54 (1).

[131] W. Coleman, B.M. Gordon, Appl. Spectrosc. 1987, 41 (7).

[132] X.K. Zhang, E.G. Lewars, R.E. March, J.M. Parnis, JPC 1993, 97 (17).

[133] W. Coleman, B.M. Gordon, Appl. Spectrosc. 1987, 41 (7).

[134] P.J. Linstrom, W. G. Mallard(Ed.), NIST Standard Reference Database Number 69, 2011.

[135] M. Förstel, P. Maksyutenko, B.M. Jones, B.-J. Sun, A.H.H. Chang, R.I. Kaiser, Submitted Manuscript 2015.

[136] R.J.A. Grim, J.M. Greenberg, M.S. DeGroot, F. Baas, W.A. Schutte, B. Schmitt, Astron. Astrophys. Supp. Ser. 1989, 78 (2).

[137] B.M. Jones, C.J. Bennett, R.I. Kaiser, ApJ 2011, 734 (2).

[138] W. Hagen, Ph.D., University of Leiden, 1982.

[139] C.J. Bennett, C.S. Jamieson, R.I. Kaiser, P\&SS 2008, 56 (9).

[140] C.J. Bennett, C.S. Jamieson, R.I. Kaiser, PCCP 2010, 12 (16).

[141] A.P. Sylwester, P.B. Dervan, J. Am. Chem. Soc. 1984, 106 (16).

[142] W. Zheng, D. Jewitt, Y. Osamura, R.I. Kaiser, ApJ 2008, 674 (2).

[143] J.R. Durig, S.F. Bush, E.E. Mercer, JChPh 1966, 44 (11). 
[144] W.J. Zheng, R.I. Kaiser, JPCA 2010, 114 (16).

[145] K. Demyk, E. Dartois, L. d'Hendecourt, A\&A 1998, 339.

[146] J.P. Ferris, E.A. Williams, D.E. Nicodem, J.S. Hubbard, G.E. Voecks, Natur 1974, 249 (5456).

[147] P.A. Gerakines, W.A. Schutte, P. Ehrenfreund, A\&A 1996, 312 (1).

[148] R.L. Hudson, M.H. Moore, Icar 2000, 145 (2).

[149] Y.J. Chen, A. Ciaravella, G.M.M. Caro, C. Cecchi-Pestellini, A. Jiménez-Escobar, K.J. Juang, T.S. Yih, ApJ 2013, 778 (2).

[150] C.S. Jamieson, A.M. Mebel, R.I. Kaiser, Astrophy. J. Suppl. Ser. 2006, 163 (1).

[151] A. Aspiala, J. Murto, P. Stén, Chem. Phys. 1986, 106 (3).

[152] J. Ceponkus, W. Chin, M. Chevalier, M. Broquier, A. Limongi, C. Crépin, JChPh 2010, 133 (9).

[153] P. Gerakines, W. Schutte, P. Ehrenfreund, A\&A 1996, 312.

[154] P. Modica, M.E. Palumbo, A\&A 2010, 519 (A22).

[155] P. Modica, M.E. Palumbo, G. Strazzulla, P\&SS 2012, 73 (1).

[156] Y.S. Kim, R.I. Kaiser, ApJ 2012, 758 (1).

[157] F. Bell, Q.N. Ruan, A. Golan, P.R. Horn, M. Ahmed, S.R. Leone, M. Head-Gordon, J. Am. Chem. Soc. 2013, 135 (38).

[158] L. Zhou, S. Maity, M. Abplanalp, A. Turner, R.I. Kaiser, ApJ 2014, 790 (1).

[159] A. Coustenis, B. Schmitt, R.K. Khanna, F. Trotta, P\&SS 1999, 47 (10-11).

[160] C. Ennis, H. Yuan, S. Sibener, R.I. Kaiser, PCCP 2011, 13 (39).

[161] Y.S. Kim, C.J. Bennett, C. Li-Hsieh, K.O. Brien, R.I. Kaiser, ApJ 2010, 711 (2).

[162] C.J. Bennett, C.S. Jamieson, R.I. Kaiser, PCCP 2009, 11 (21).

[163] M.J. Abplanalp, A. Borsuk, B.M. Jones, R.I. Kaiser, 2015.

[164] S. Fujii, N. Osaka, M. Akita, K. Itoh, JPC 1995, 99 (18).

[165] S. Breda, I. Reva, R. Fausto, JPCA 2012, 116 (9).

[166] F. Winther, S. Meyer, F.M. Nicolaisen, JMoSt 2002, 611 (1).

[167] W. Zheng, R.I. Kaiser, CPL 2007, 450 (1-3).

[168] C.J. Bennett, T. Hama, Y.S. Kim, M. Kawasaki, R.I. Kaiser, ApJ 2011, 727 (1).

[169] C.J. Bennett, B. Jones, J.E. Knox, J. Perry, Y.S. Kim, R.I. Kaiser, ApJ 2010, 723 (1).

[170] W.J. Zheng, D. Jewitt, R.I. Kaiser, CPL 2007, 435 (4-6).

[171] W. Zheng, D. Jewitt, R.I. Kaiser, PCCP 2007, 9 (20).

[172] W.J. Zheng, D. Jewitt, R.I. Kaiser, JPCA 2009, 113 (42).

[173] H.Y. Wang, J.A. Eyre, L.M. Dorfman, JChPh 1973, 59 (9).

[174] H.-J. Werner, C. Bauer, P. Rosmus, H.-M. Keller, M. Stumpf, R. Schinke, JChPh 1995, $102(9)$.

[175] C.J. Bennett, S.B. Morales, S.D. Le Picard, A. Canosa, I.R. Sims, Y. Shih, A. Chang, X. Gu, F. Zhang, R.I. Kaiser, PCCP 2010, 12 (31).

[176] C.S. Jamieson, A.M. Mebel, R.I. Kaiser, Astrophys. J. Suppl. Ser. 2006, 163 (1).

[177] J.E. Bertie, M.M. Morrison, JChPh 1980, 73 (10).

[178] D. Frost, S. Lee, C. McDowell, N. Westwood, JChPh 1976, 64 (11).

[179] J.E. Stewart, JChPh 1957, 26 (2).

[180] P.A. Gerakines, W.A. Schutte, J.M. Greenberg, E.F. van Dishoeck, A\&A 1995, 296 (3).

[181] G. van der Zwet, L.J. Allamandola, F. Baas, J. Greenberg, JMoSt 1989, 195 (1).

[182] J.R. Brucato, G.A. Baratta, G. Strazzulla, A\&A 2006, 455 (2).

[183] R.L. Hudson, M.H. Moore, A\&A 2000, 357 (2). 
[184] J.E. Bertie, S.L. Zhang, JMoSt 1997, 413 (1).

[185] A. Brock, N. Minacamilde, C. Manzanares, JPC 1994, 98 (18).

[186] R.B. Bohn, S.A. Sandford, L.J. Allamandola, D.P. Cruikshank, Icar 1994, 111 (1).

[187] T. Shimanouchi, Tables of Molecular Vibrational Frequencies Consolidated Volume I, National Bureau of Standards, Maryland, 1972.

[188] E. Rytter, D.M. Gruen, AcSpA 1979, 35 (3).

[189] D.R. Cowieson, A.J. Barnes, W.J. Orvillethomas, J. Raman Spectrosc. 1981, 10 (1).

[190] J. Comeford, J.H. Gould, JMoSp 1961, 5 (1).

[191] I.W. Levin, R.A. Pearce, W. Harris, JChPh 1973, 59 (6).

[192] C.J. Bennett, R.I. Kaiser, ApJ 2005, 635 (2). 


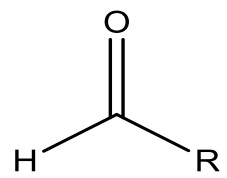

(1)

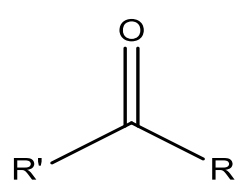

(2)

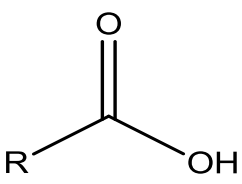

(3)

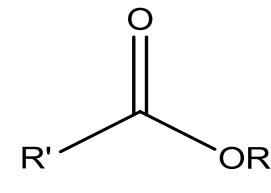

(4)

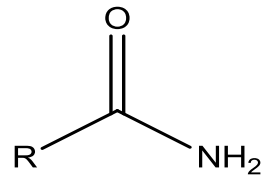

(5)

Figure 1: Key classes of complex organic molecules observed in the gas phase of the interstellar medium (ISM) covering cold molecular clouds and star forming regions. 


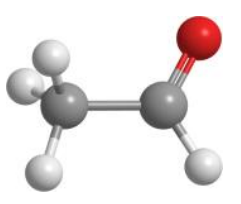

Acetaldehyde $\left(10.23 \mathrm{eV} ; 0 \mathrm{~kJ} \mathrm{~mol}^{-1}\right)$

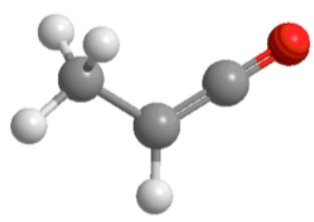

Methylketene $\left(8.95 \mathrm{eV} ; 0 \mathrm{~kJ} \mathrm{~mol}^{-1}\right)$

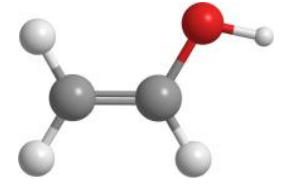

Vinyl Alcohol $\left(9.33 \mathrm{eV} ; 43 \mathrm{~kJ} \mathrm{~mol}^{-1}\right)$

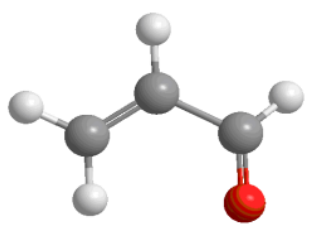

Propenal $\left(10.11 \mathrm{eV} ; 2 \mathrm{~kJ} \mathrm{~mol}^{-1}\right)$

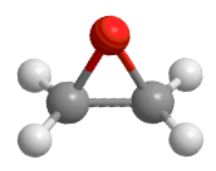

Ethylene Oxide $\left(10.56 \mathrm{eV} ; 118 \mathrm{~kJ} \mathrm{~mol}^{-1}\right)$

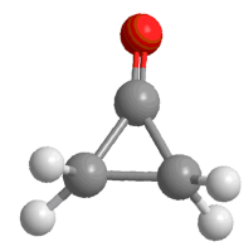

Cyclopropanone $\left(9.10 \mathrm{eV} ; 102 \mathrm{~kJ} \mathrm{~mol}^{-1}\right)$

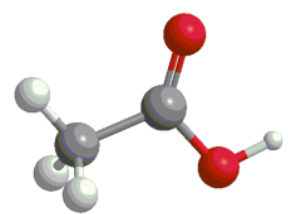

Acetic Acid (10.65 eV; $0 \mathrm{~kJ} \mathrm{~mol}^{-1}$ )

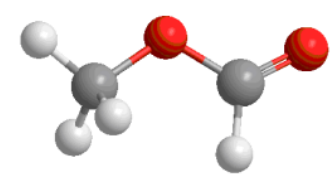

Methyl Formate $\left(10.84 \mathrm{eV} ; 80 \mathrm{~kJ} \mathrm{~mol}^{-1}\right)$

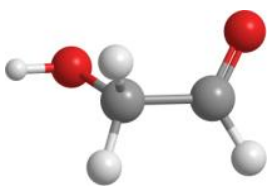

Glycoladehyde $\left(10.20 \mathrm{eV} ; 116 \mathrm{~kJ} \mathrm{~mol}^{-1}\right)$

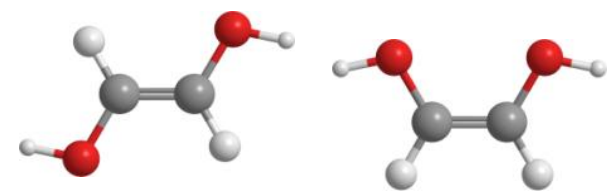

(E/Z)-ethen-1,2-diol $\left(9.62 \mathrm{eV} ; 116 \mathrm{~kJ} \mathrm{~mol}^{-1}\right)$

Figure 2: Three groups of astrophysically relevant structural isomer $\mathrm{C}_{2} \mathrm{H}_{4} \mathrm{O}, \mathrm{C}_{3} \mathrm{H}_{4} \mathrm{O}$, and $\mathrm{C}_{2} \mathrm{H}_{4} \mathrm{O}_{2}$, along with their ionization energies and relative stabilities with respect to the most stable isomer within one group given in parenthesis [134]. 


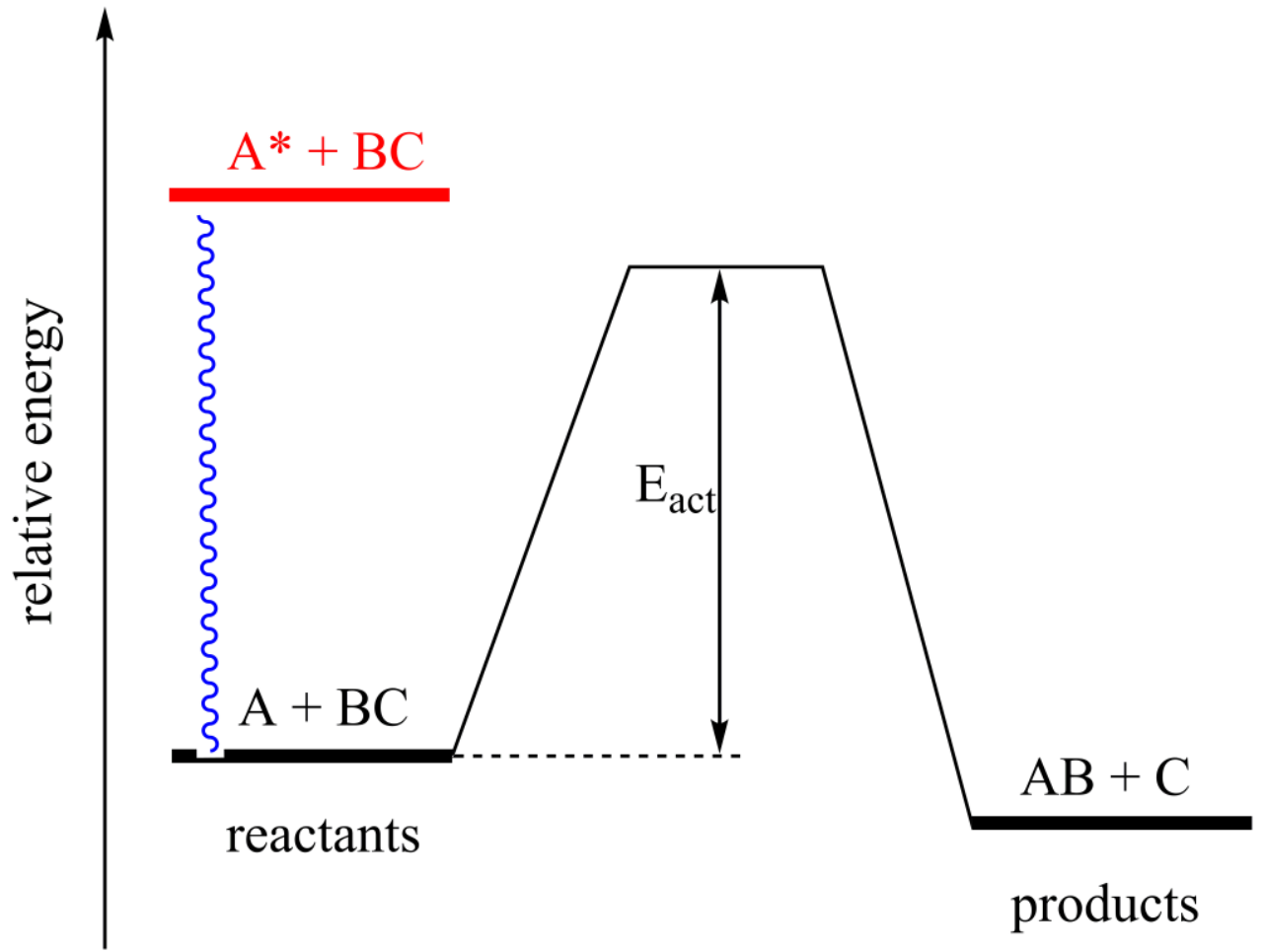

Figure 3: Schematic representation of a chemical reaction passing a classical activation barrier from the reactants to the products. Interaction with ionizing radiation may increase the energy of one reactant $\left(\mathrm{A}^{*}\right)$ to overcome the activation energy. 


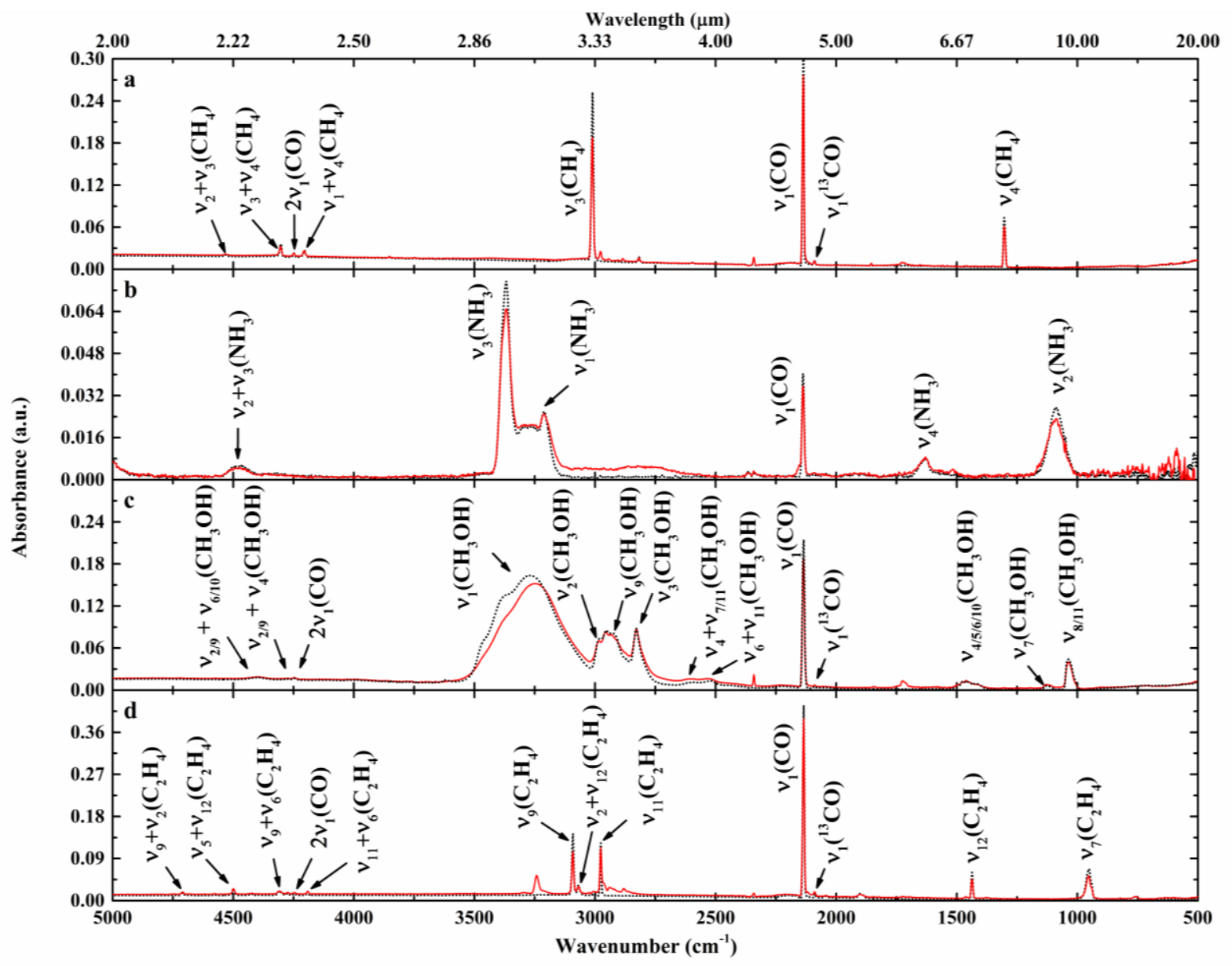

Figure 4: Infrared spectra before (black) and after irradiation (red) of four ice systems: (a) $\mathrm{CO}$ $\mathrm{CH}_{4}$. (b) $\mathrm{CO}-\mathrm{NH}_{3}$. (c) $\mathrm{CO}-\mathrm{CH}_{3} \mathrm{OH}$. (d) $\mathrm{CO}-\mathrm{C}_{2} \mathrm{H}_{4}$. The infrared assignments before and after the irradiation are compiled in Tables $2 \mathrm{a}$ to $2 \mathrm{~d}[28,29,135,163]$. 


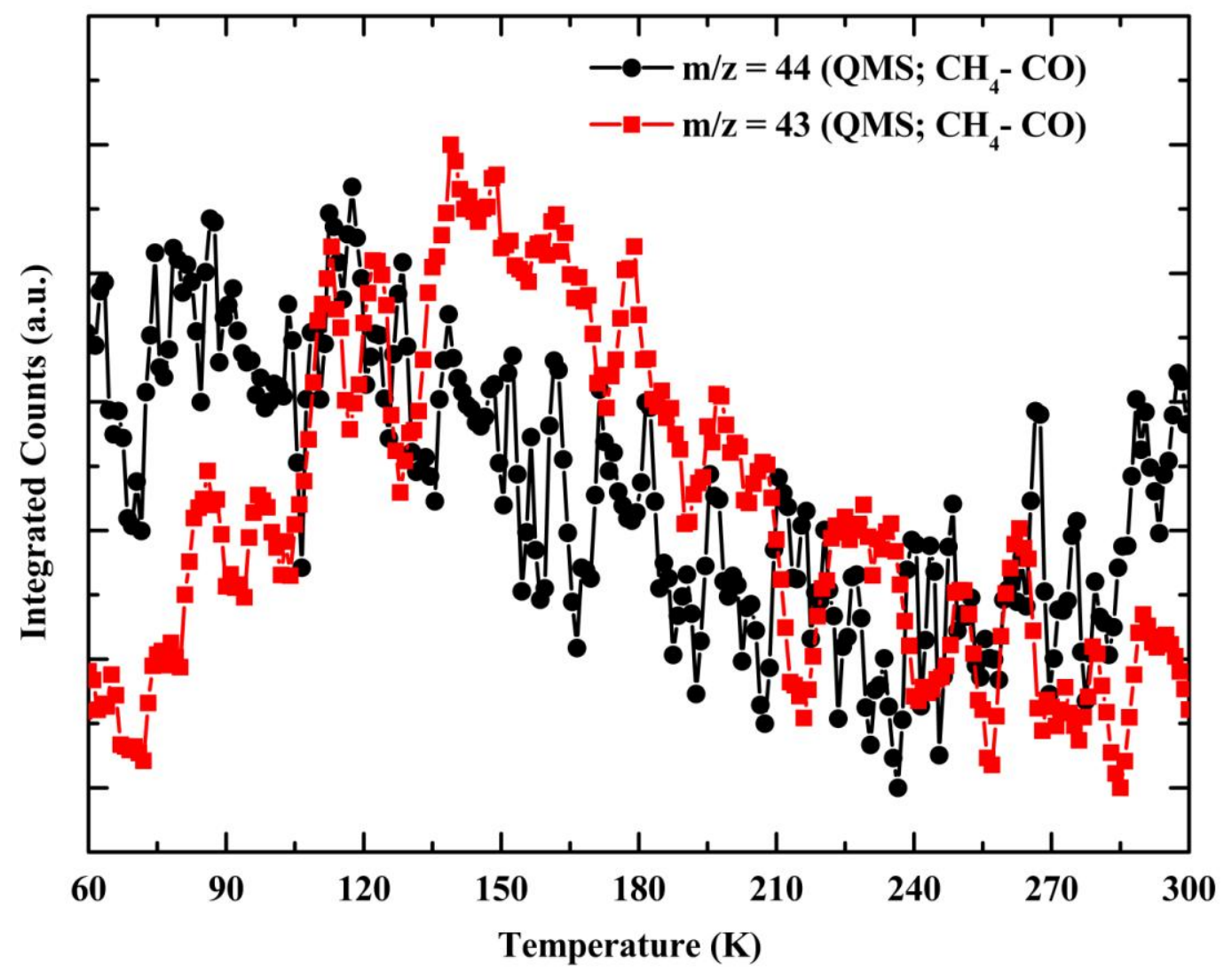

Figure 5: Integrated ion counts recorded by a quadrupole mass spectrometer operating in residual gas analyzer mode with an electron impact ionization source at $70 \mathrm{eV} \mathrm{[29].}$ 
<smiles>NCC(=O)NCC(=O)O</smiles>

Gly-Gly<smiles>CC(N)C(=O)NC(C)C(=O)O</smiles>

Ala-Ala<smiles>C[C@H](N)C(=O)NCC(=O)O</smiles>

Ala-Gly

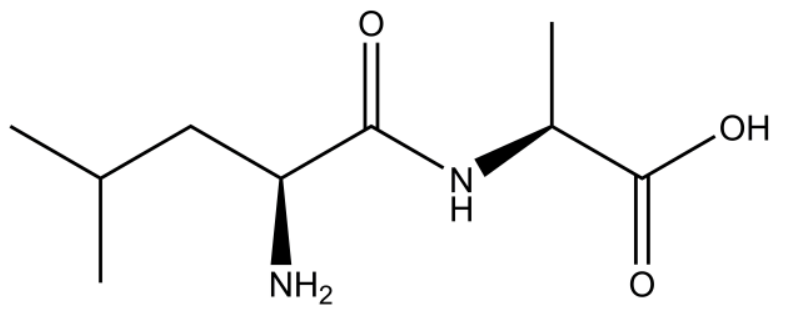

Leu-Ala

Figure 6: Structures of dipeptides identified in residues of electron irradiated carbon dioxide, ammonia, and hydrocarbon ices [52]. 


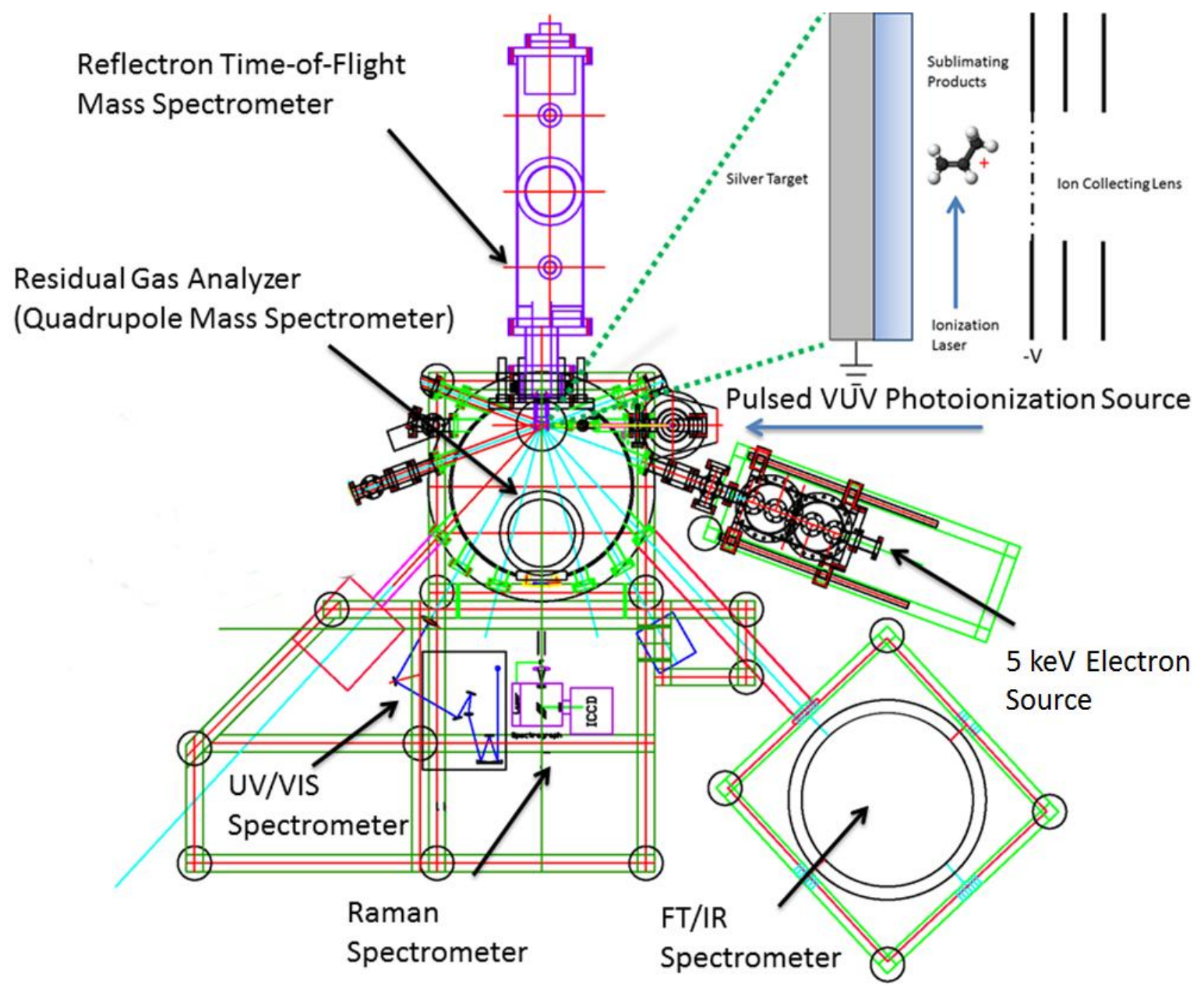

Figure 7: Top-view schematic of the UHV simulation chamber along with the interfaced analytical devices [25]. 

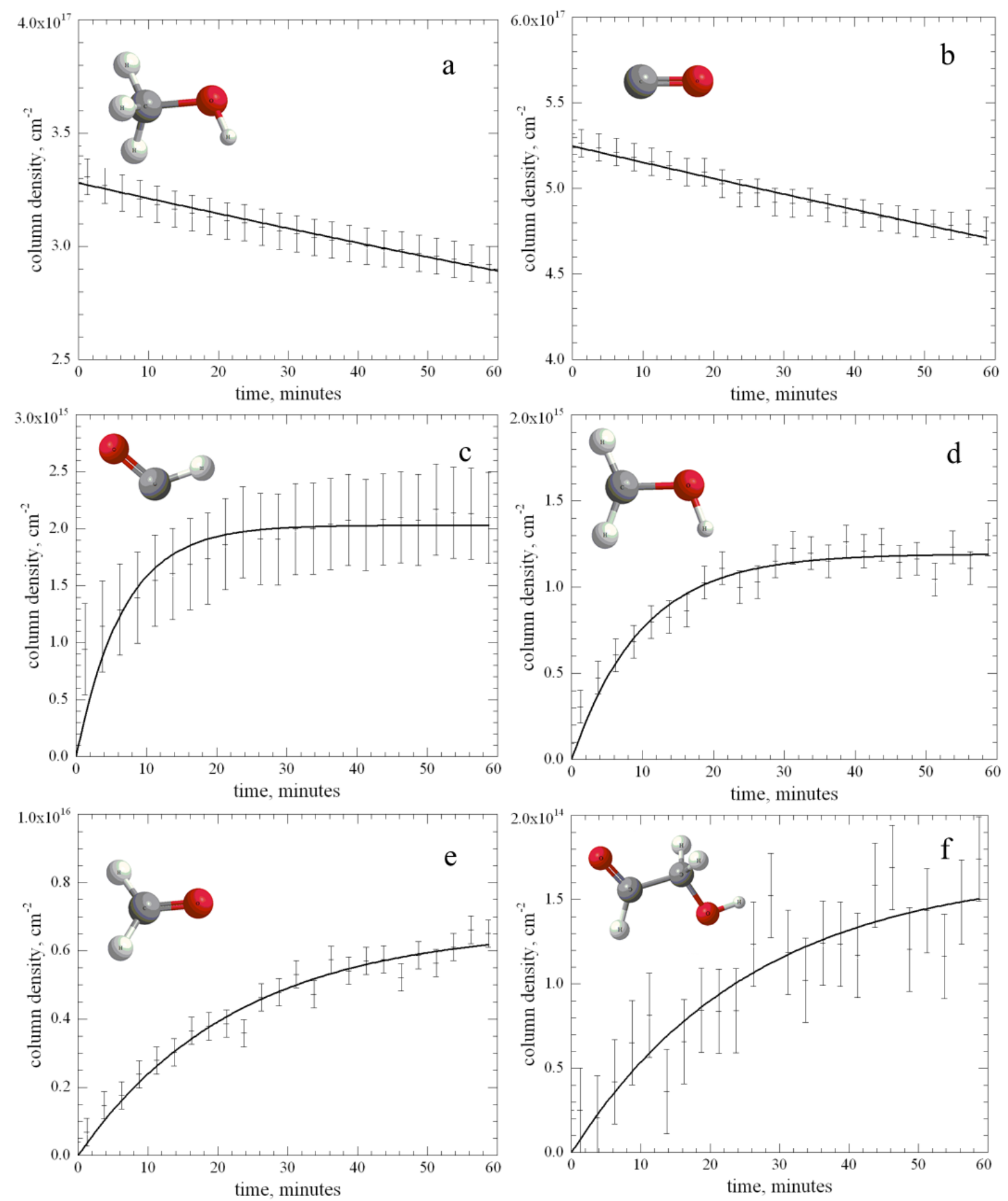


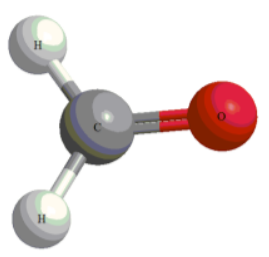

Formaldehyde

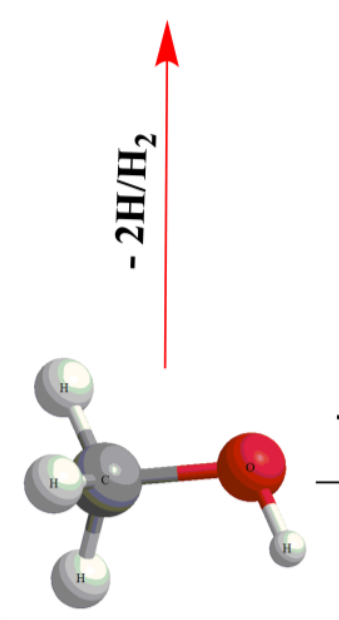

Methanol

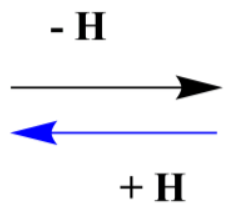

$+\mathbf{H}$

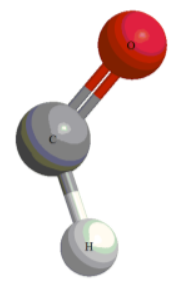

Formyl radical

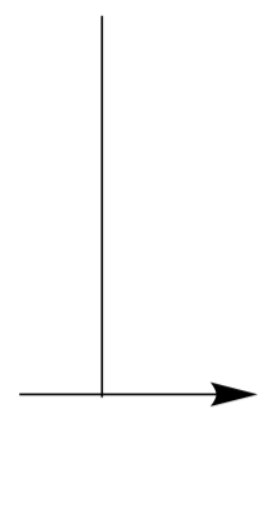

Hydroxymethyl

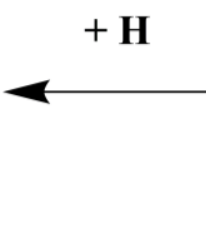

\section{Carbon monoxide}

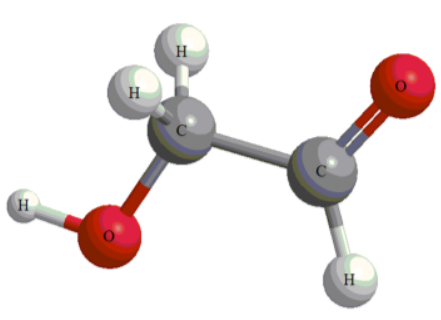

Glycolaldehyde radical

Figure 8: (Top) Kinetic fitting of time-dependent profiles for several species related to the formation of glycolaldehyde. (Bottom) The reaction scheme derived from the model underlying these kinetic fits $[28,39]$. 


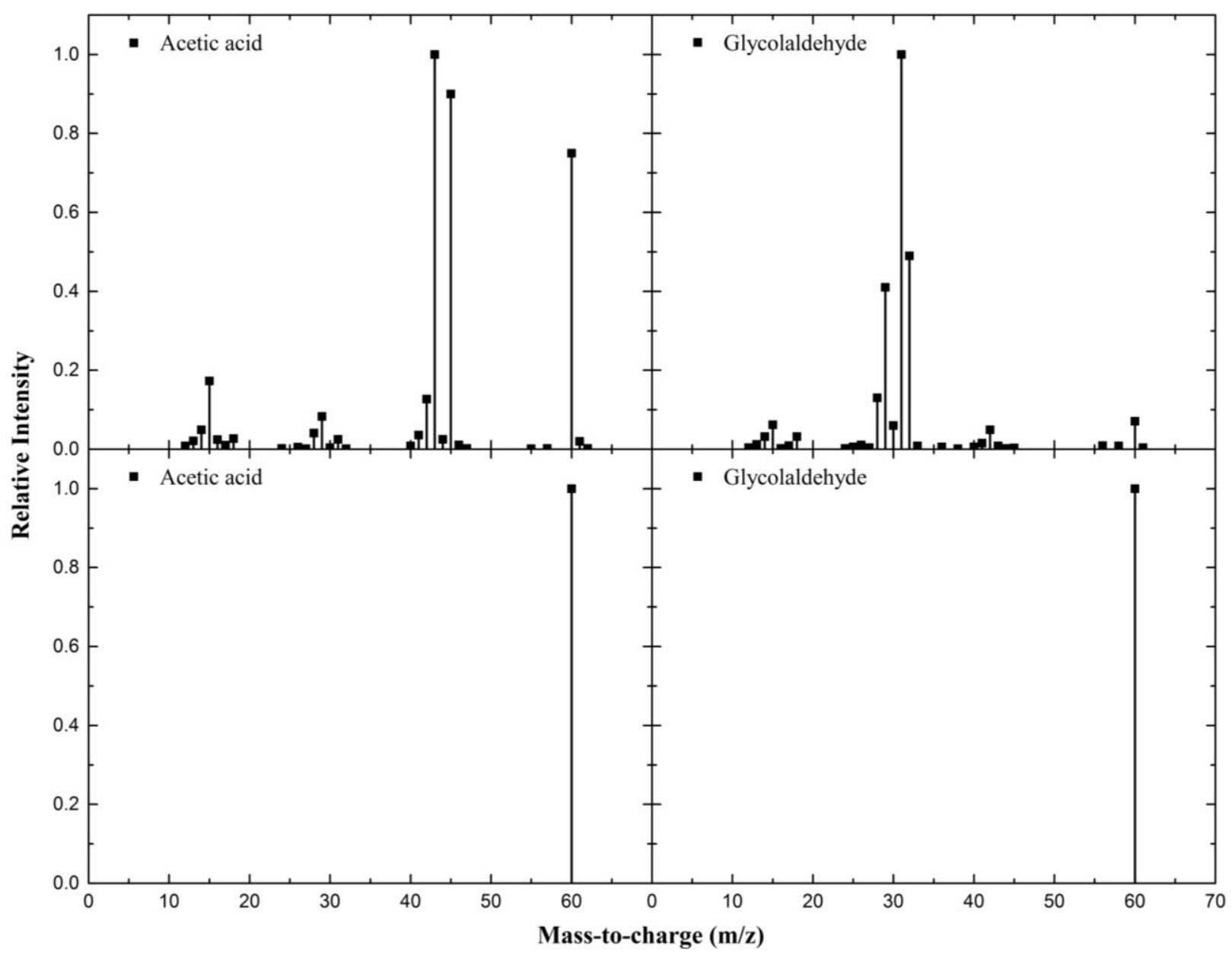

Figure 9: Fragmentation patterns of the $\mathrm{C}_{2} \mathrm{H}_{4} \mathrm{O}_{2}$ isomers acetic acid (left; $\mathrm{CH}_{3} \mathrm{COOH}$ ) and glycolaldehyde (right; $\mathrm{HCOCH}_{2} \mathrm{OH}$ ) as observed when using electron impact ionization mass spectrometry (top) and PI-ReTOF-MS (bottom) [134]. 

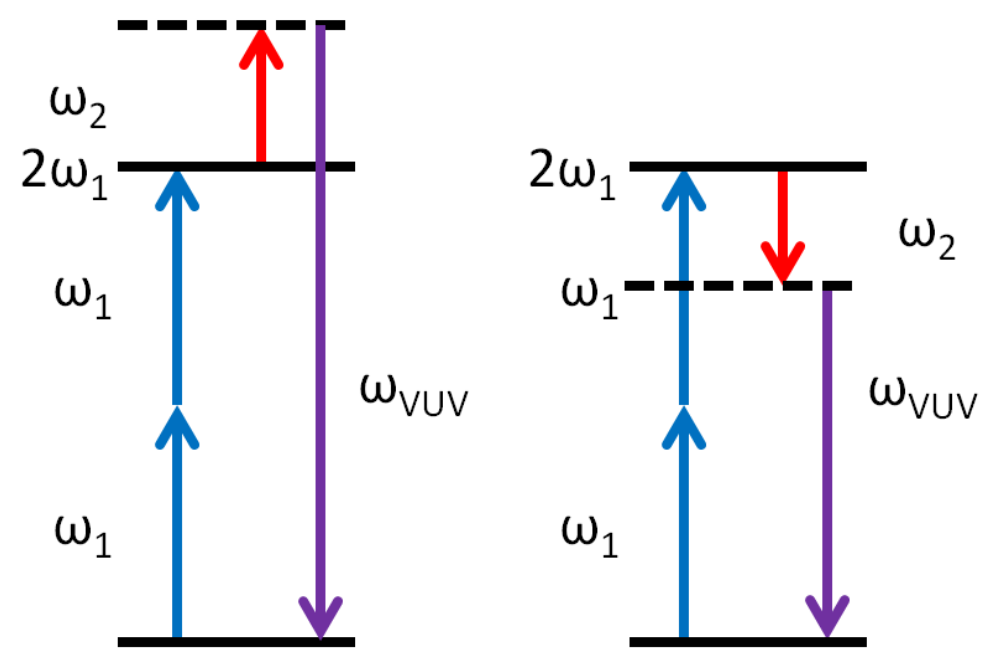

$$
\omega_{\mathrm{VUV}}=2 \omega_{1}+\omega_{2} \quad \omega_{\mathrm{VuV}}=2 \omega_{1}-\omega_{2}
$$

Figure 10: Schematic of the four wave resonant mixing principle in a rare gas (non-linear medium) to produce vacuum-ultraviolet light (VUV). The blue arrows represent wavelength one $\left(\omega_{1}\right)$, red arrows correspond to the second wavelength used $\left(\omega_{2}\right)$, and purple arrows designate the VUV photon that is produced ( $\left.\omega_{\mathrm{VUV}}\right)$. Typically, $\omega_{1}$ is a UV photon and $\omega_{2}$ is a photon in the visible region. Four wave sum mixing is shown on the left. Here, two photons of wavelength $\omega_{1}$ $\left(2 \omega_{1}\right)$ are added to by $\omega_{2}$ producing $\omega_{\mathrm{VUV}}\left(\omega_{\mathrm{VUV}}=2 \omega_{1}+\omega_{2}\right)$. Four wave difference mixing is depicted on the right. Here, the difference of wavelength $\omega_{1}\left(2 \omega_{1}\right)$ and $\omega_{2}$ produce $\omega_{\mathrm{VUV}}\left(\omega_{\mathrm{VUV}}=\right.$ $\left.2 \omega_{1}-\omega_{2}\right)$. 

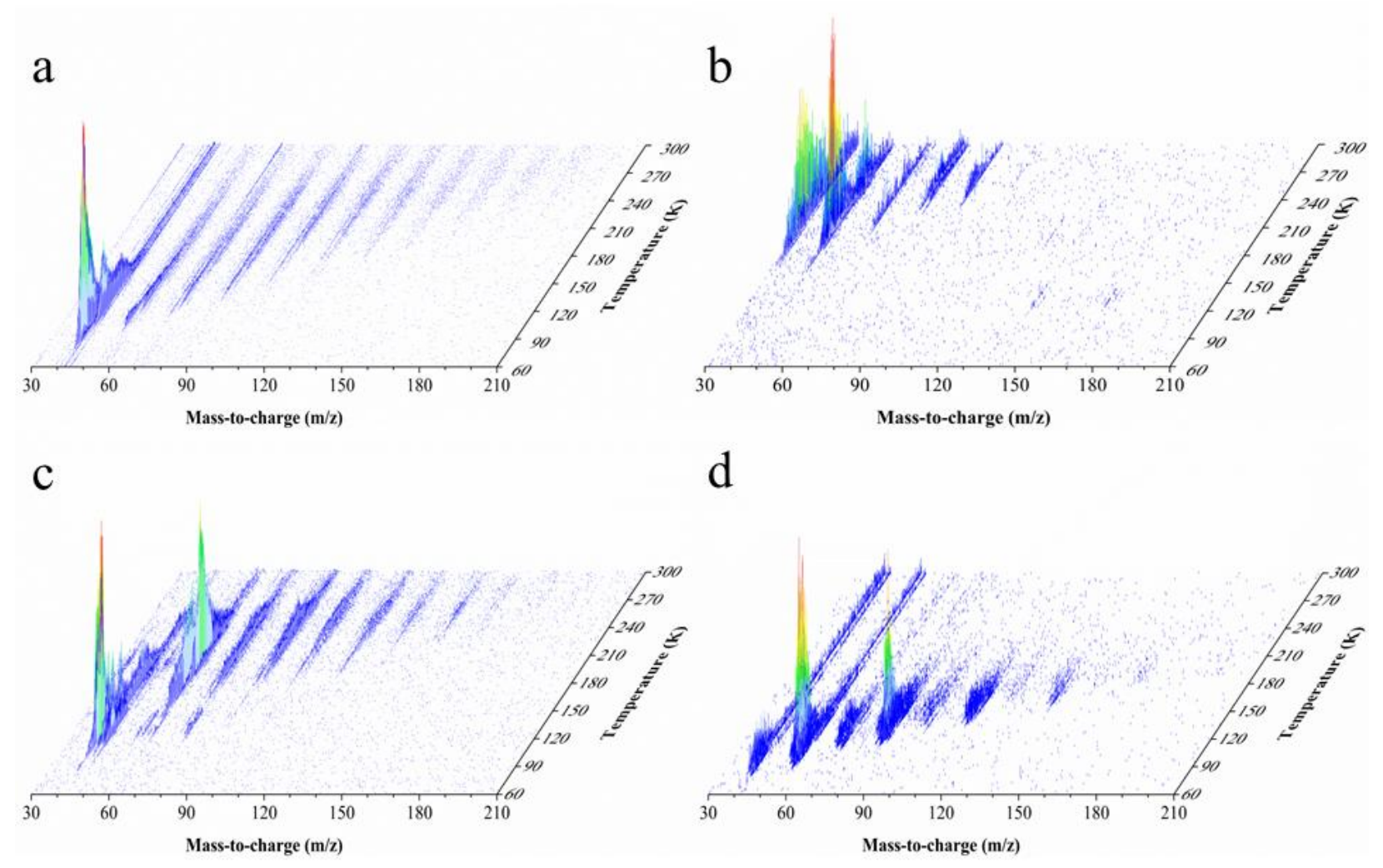

d

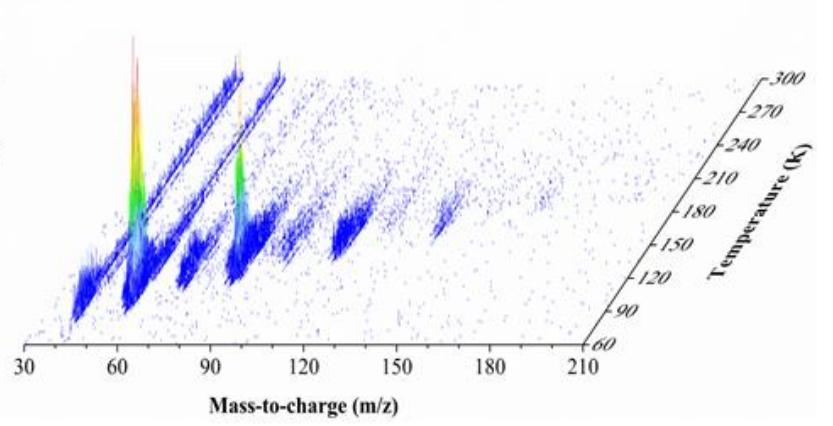

Figure 11: 3D visualization of the PI-ReTOF-MS data of the irradiated ices collected during TPD. The intensity is shown as a change in color from blue (low intensity) to red (high intensity). Each system has been scaled to its highest ion count. (a) $\mathrm{CO}-\mathrm{CH}_{4}$. (b) $\mathrm{CO}-\mathrm{NH}_{3}$. (c) CO- $\mathrm{CH}_{3} \mathrm{OH}$. (d) $\mathrm{CO}-\mathrm{C}_{2} \mathrm{H}_{4}$ systems [28, 29, 135, 163]. 


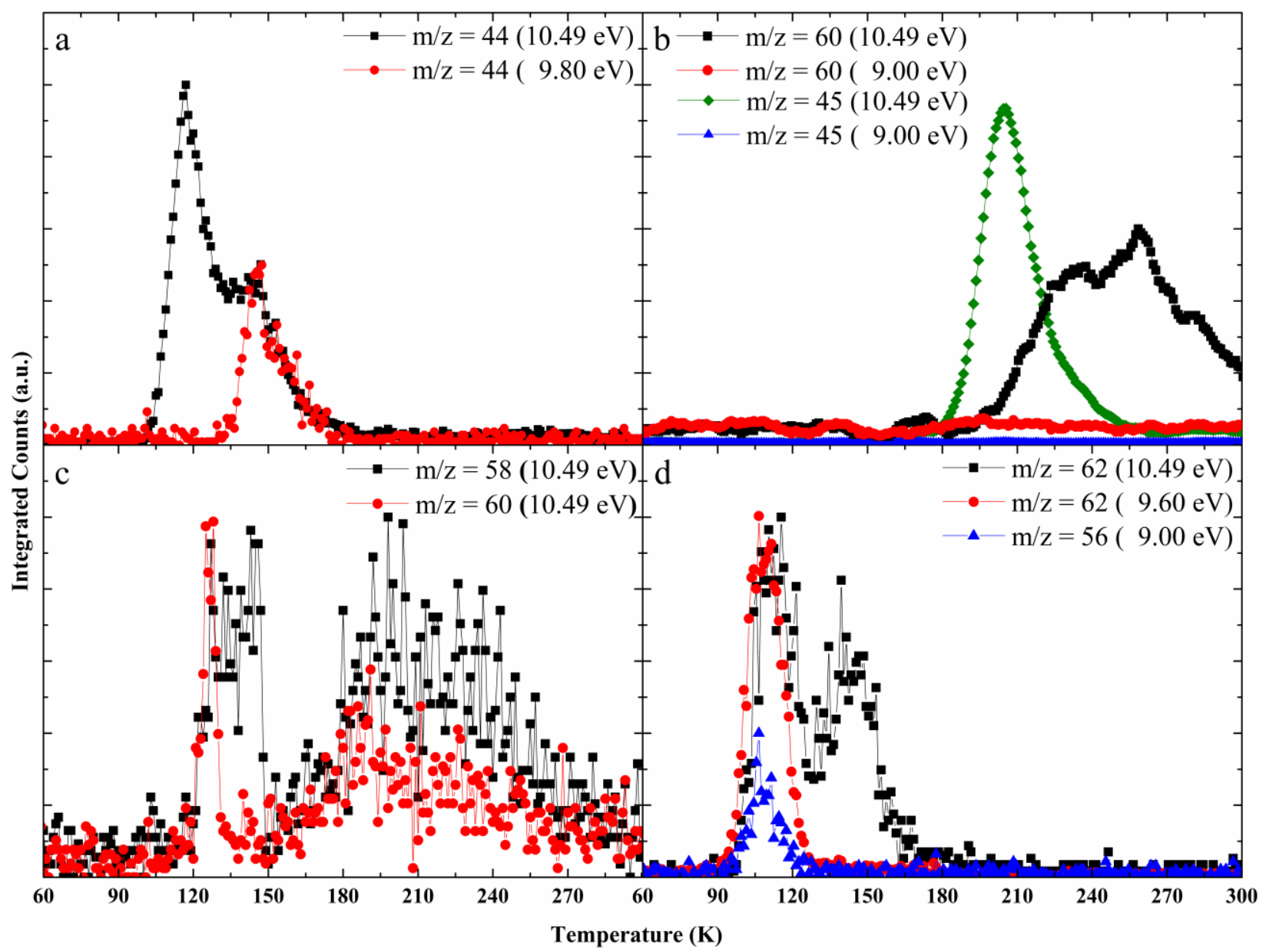

Figure 12: (a) TPD profiles of $\mathrm{m} / \mathrm{z}=44\left(\mathrm{C}_{2} \mathrm{H}_{4} \mathrm{O}^{+}\right)$subliming from the irradiated $\mathrm{CO}-\mathrm{CH}_{4}$ ices recorded at photoionization energies of $10.49 \mathrm{eV}$ (black) and $9.80 \mathrm{eV}$ (red). (b) TPD profiles of $\mathrm{m} / \mathrm{z}=45\left(\mathrm{CH}_{3} \mathrm{NO}^{+}\right)$and $\mathrm{m} / \mathrm{z}=60\left(\mathrm{CH}_{4} \mathrm{~N}_{2} \mathrm{O}^{+}\right)$subliming from the irradiated $\mathrm{CO}-\mathrm{NH}_{3}$ ices recorded at photoionization energies of $10.49 \mathrm{eV}$ (green; black) and $9.00 \mathrm{eV}$ (blue; red). (c) TPD profiles of $\mathrm{m} / \mathrm{z}=58\left(\mathrm{C}_{3} \mathrm{H}_{6} \mathrm{O}^{+}\right.$; black $)$and $\mathrm{m} / \mathrm{z}=60\left(\mathrm{C}_{3} \mathrm{H}_{6}{ }^{18} \mathrm{O}^{+}\right.$; red $)$subliming from the irradiated $\mathrm{CO}-\mathrm{CH}_{3} \mathrm{OH}$ and $\mathrm{C}^{18} \mathrm{O}-\mathrm{CH}_{3}{ }^{18} \mathrm{OH}$ ices, respectively, recorded at a photoionization energy of $10.49 \mathrm{eV}$. (d) TPD profiles of $\mathrm{m} / \mathrm{z}=62\left(\mathrm{C}_{3} \mathrm{D}_{4}{ }^{18} \mathrm{O}^{+}\right.$; black), $\mathrm{m} / \mathrm{z}=62\left(\mathrm{C}_{3} \mathrm{D}_{4}{ }^{18} \mathrm{O}^{+}\right.$; red $)$, and $\mathrm{m} / \mathrm{z}=$ $56\left(\mathrm{C}_{3} \mathrm{H}_{4} \mathrm{O}^{+}\right.$; blue $)$subliming from the irradiated $\mathrm{CO}-\mathrm{C}_{2} \mathrm{H}_{4}$ and $\mathrm{C}^{18} \mathrm{O}-\mathrm{C}_{2} \mathrm{D}_{4}$ ices recorded at photoionization energies of $10.49 \mathrm{eV}, 9.60 \mathrm{eV}$, and $9.00 \mathrm{eV}$, respectively [28, 29, 135, 163]. 


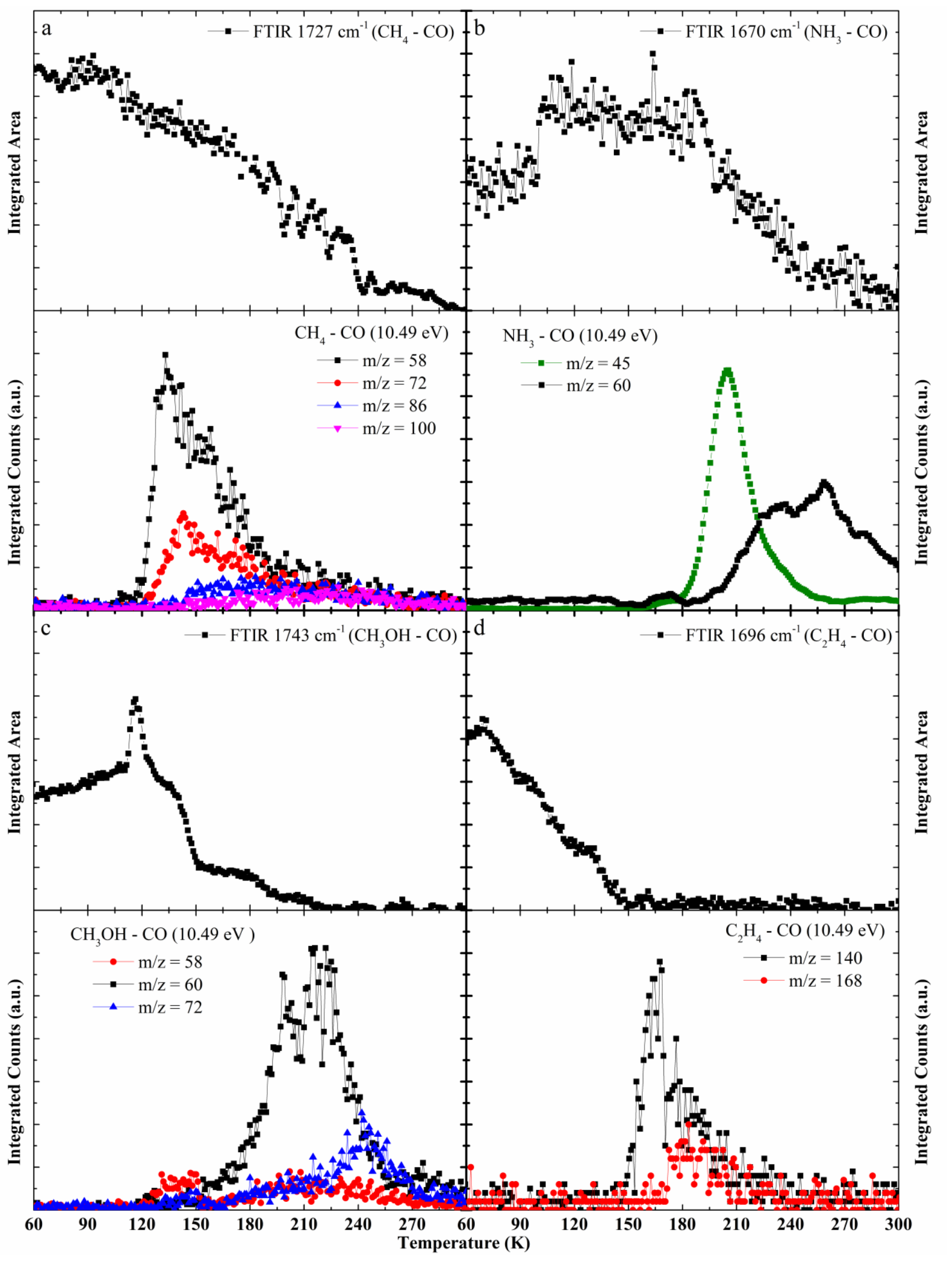


Figure 13: Comparison of the TPD profiles of specific species recorded via PI-ReTOF-MS (top) with selected temperature-dependent absorption profiles (bottom). (a) $\mathrm{CO}-\mathrm{CH}_{4}$, (b) $\mathrm{CO}-\mathrm{NH}_{3}$, (c) $\mathrm{CO}-\mathrm{CH}_{3} \mathrm{OH}$, (d) $\mathrm{CO}-\mathrm{C}_{2} \mathrm{H}_{4}$ system $[28,29,135,163]$. 


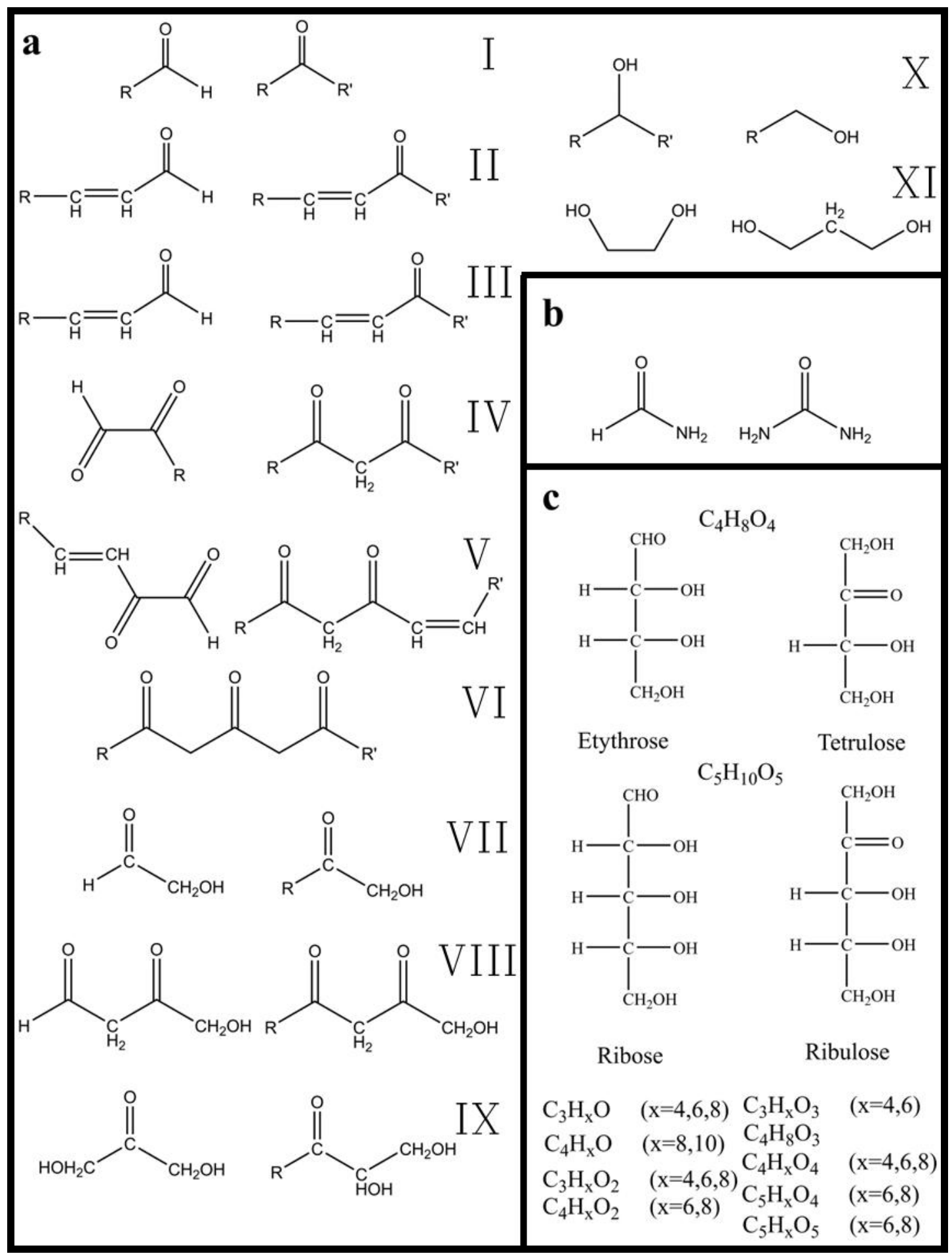

Figure 14: Key classes of COMs identified in prototype ice mixtures. (a) $\mathrm{CO}-\mathrm{CH}_{4}$, (b) $\mathrm{CO}-$ $\mathrm{NH}_{3}$, (c) $\mathrm{CO}-\mathrm{CH}_{3} \mathrm{OH}[28,29,135]$. 


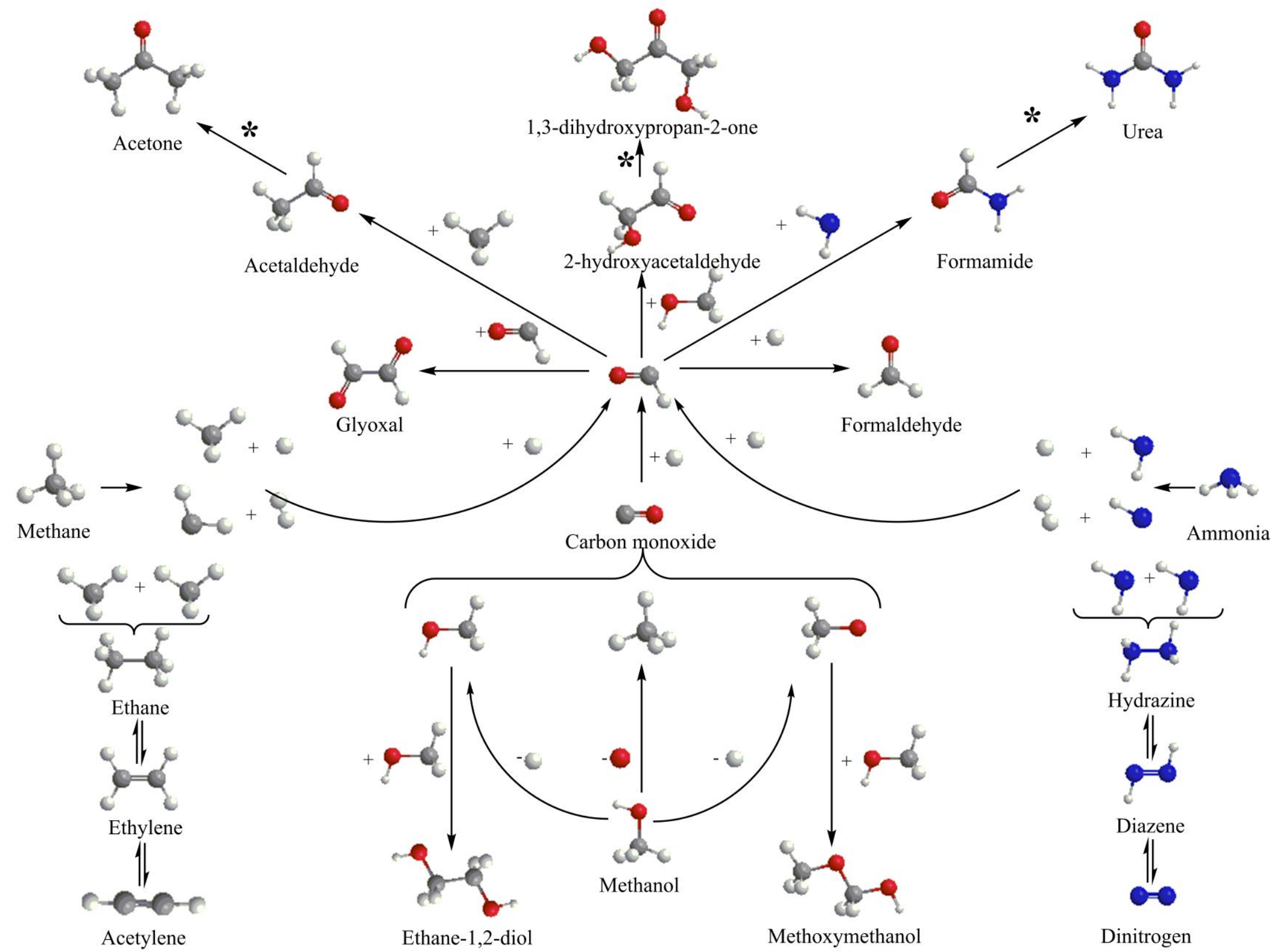


Figure 15: Reaction scheme for the formation of complex organic molecules starting from simple molecules such as methane, methanol, and ammonia reacting with carbon monoxide. *: Reaction pathways to be elucidated. Carbon, hydrogen, oxygen, and nitrogen atoms are color coded in black, grey, red, and blue, respectively. 


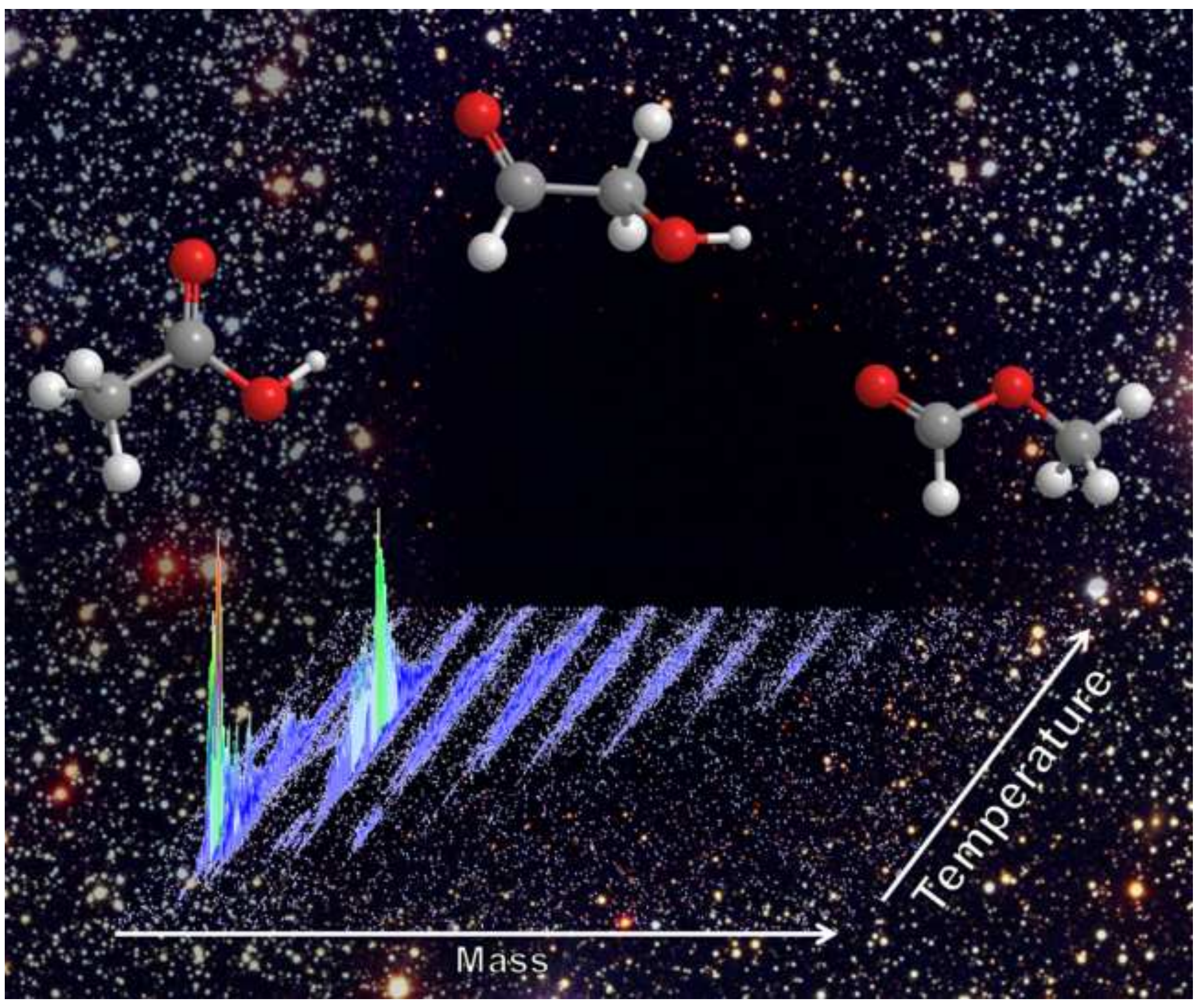




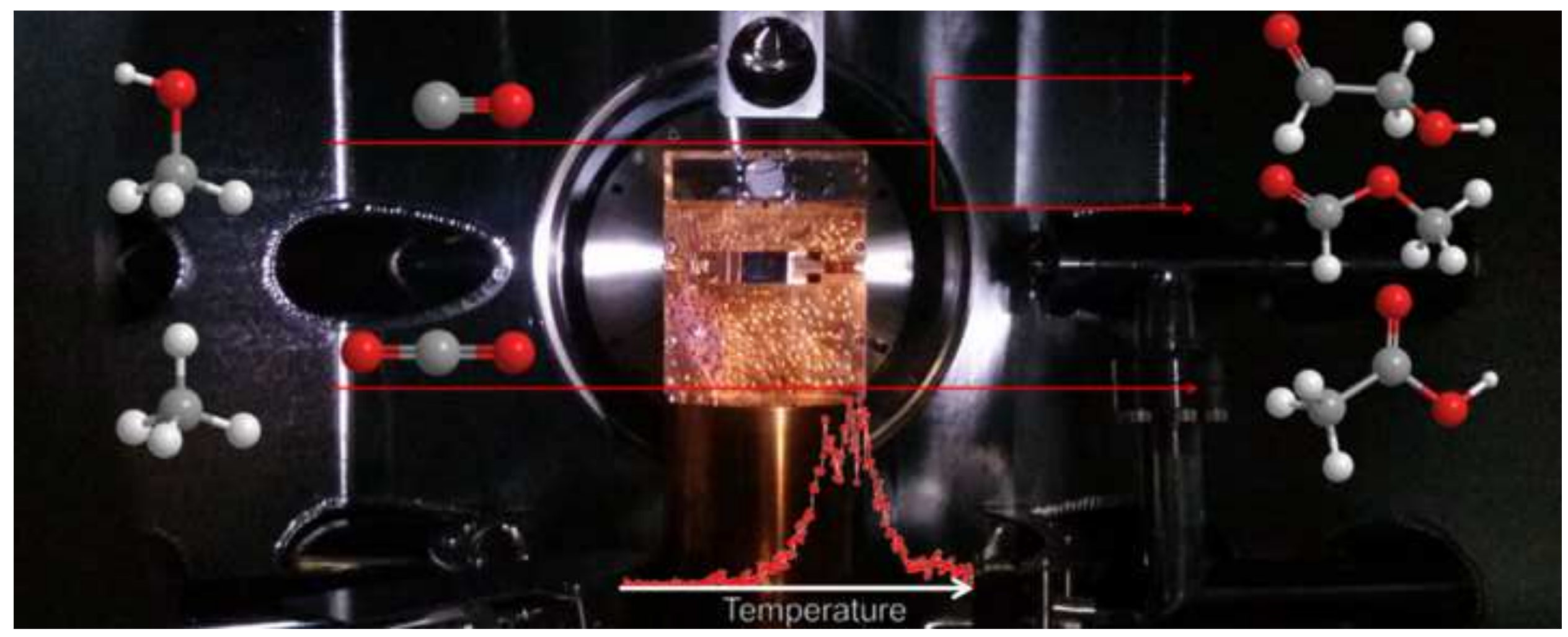

